\title{
CONTRIBUCION AL ESTUDIO DEL ERITEMA NUDOSO
}

\section{Por los Dres. ALFREDO WIEDERHOLD, AIFONSO COSTA Y ALBERTO GUZMAN}

El presente trabajo lo emprendimos en el deseo de estudiar los diferentes puntos de interés que encierra el eritem. nudoso bajo el punto de vista de la pediatría chilena. Hasta la fécha nos hemos atenido siempre a la experiencia de autores extranjeros, especialmente los nórdicos. a la cabeza de los cuales se encuentra A. Wallgten. En estos últimos años se estudió con afán todo lo referente a la patogenia de esta $\mathrm{ma}$ rifestación tuberculosa cutánea. Especialmente es ese capitulo el que más nos interesó para formarnos un criterio propio. No nos interesamos por estudiar el eritema contusiforme en toda su amplitud clínica, porque ya es demasiado conocido por todos. Enfocamos nuestro estudio desde el punto de vista de jas condiciones etiológicas del eritema nudoso con respecto a la edad. al sexo y a la estación del año. También nos interesó el estudio de ciertos caracteres clínicos, como set. la localización. La radiología toráxica en el eritema nudos? fué observada y aun fijada en la mayoria de los casos con $\mathrm{ra}^{-}$ diografias pulmonares. Citames también dos casos de eritéma nudoso con puerta de entrada extra-pulmonar del B. de Koch per una vía poco conocida. Anotamos con detalle las reacciones tuberculínitas en esta afección. como asimismo th velocidad de sedimentación.

Según Ernberg. el eritema nurloso es una reacción anafiláctica desencadenada por un foco tuberculoso básico grincipal, una especie de autorreacción de tuberculina. El Prof. Ffaundler, en su clase decía que en la infancia el eritema n!ndeso representaba una "autopirquetización". Esta reacción

(1) Trabajo yerent do a i.a Scciedad Chilana de Pediarriz, sesión dol i de oclubre de 1942. 
anafiláctica sólo se presenta con la infección tuberculosa en individuos predispuestos a dicha reacción. Se realizó la investigación del $\mathrm{B}$. de Koch en la expectoración recogida por lavado gástrico. Se hizo casi exclusivamente la investigación directa.

Especial interés dedicamos a investigar el $B$. de Koch en los nódulos cutáneos por medio de la inoculación experimental y el examen directo al microscopio de las lesiones nodulares. El estudio morfológico de los nódulos nos detuvo algún tiempo con el objeto de saber cuál de los conceptos al respect? es el más ajustado a la realidad, si es una lesión inflamatoria banal o una inflamación específica tuberculosa, como alguncs sostienen.

A estos estudios ya tealizados por muchos otros autore: agregamos uno nuevo que hasta ahora ningun autor habia raalizado en el eritema nudoso. Nos referimos al examen his. topatológico y a la inoculación experimental de las adenitis satélites del etitema nudoso. La razón por la cual emprendimos esta investigación la daremos en el transcurso $d$ E esta expcsición. Por último, basándonos en la definición cínica del eritema nudoso, què lo considera como una autorreacción de tuberculina del organismo infantil, nos interesó vivamerta hacer una compatación morfológica de la bistopatología del critema nudoso y de la reacción de Mantoux.

Antes de entrar en materia, consideramos nuestro deber agradecer al colega Pedro Grove, quien tuvo la gentileza de efectuar más de 64 biopsias en el transcurso de este trabajo. por lo cual se hace partícipe de estos estudios realizados. También vayan nuestros agradecimientos a los diferentes colecas que nos facilitaron nuestra labor en los diferentes enfermos a su cargo durante estos tres últimos años.

Según Wallgren. desde el punto de vista anatómito. el ródulo eritematoso no está constituido por tejido espacíficamente tuberculose. Es, en cambio, el tipo del proceso inflimatorio agudo no específico. Níngún cuadro bistológica ha podido hallarse para probar el origen tuberculoso. Desdie el Funte de virta bacteriológice, no se puede demsetrar que ei nódulo rea producto de la actividad local del bacilo tubercalo. so, en el sitio mismo $\varepsilon_{n}$ que el nódulo se produce. En todos los exámenes hechos en tal sentido en los paises escandinavos (Entrarg, Rotnes. Wallgren). no ha sido posible demostrar la presencia del bacilo por baciloscopía directa ni por inoculación al conejillo de Indias. Algunas pocas coniunicaciones sobre el hallazgo del bacilo se han presentado en Francia' (D)- 
bré, Saens, Broca y Bernard), en la Argentina (Cibils Aguirre y Arenas) y en Polonia (Lewcowicz). Aunque estos hallazgos puedan considerarse como concluyentes, el bacilo puede haber sido aportado por mezcla can sangre conteniendo bacilos (bacilemia durante el período primario) y no indican necesariamente que las alteraciones anatómicas hayan sido producidas por la directa acción focal del agente. Los autores que han futlicado casos positivos no han podido evidenciar el bacilo sino en la minoría de los casos. Desde el punto de vista clinico, la aparición súbita de la érupción, su brusca desaparición y la tápida transformación morfológica de los nódulos es incompatible con un proceso realmente tuberculoso.

Tiebré. Sáenz y sus colaboradores sostienen que en el eritema nudoso la alergia juega un tol indiscutible en su producción. Pero ellos creen firmemente que la presencia del bacilo de Koch in situ es necesaria para la producción de la lesión, por más efimera y curable que ella sea. Ellos piensan que el fenómeno fundamental es una infección tuberculosa de un'a especial benignidad, alcanzando en un momento dado. on condiciones bien particulares, ciertas zonas de la piel. Para ellos, el eritema nudoso es una tuberculosis cutánea paucibacilat nc folicular efímera y csencialmente expresión de la invasión bacilar.

Nuestro trabajo se basa en los mismos métodos seguidos por esos autores, menos el estudio bacteriológico de la sangre para investigar en ella la presencia del bacilo de Koch. Hemos realizado el estudio de las reacciones tuberculinicas, el examen radiológico, el estudio histológico de los nódulos y el eșr $\mathbf{u}^{\prime \prime}$ dio bacteriológico de los nódulos y de la expectoración. Consideramos innecesario el estudio bacteriológico de la sangre por el método de Loewenstein. por cuanto es un procedimiento muy discutido $y$ ya dejado a un lado hoy en día. Debré y colaboradores recurrieron a la inoculación experimental de la sangre, obteniendo 5 resultados positivos sobre 35 casos. El nódulo se extraía por biopsia y ese trozo de piel se dividia por la mitad. Una mitad se enviaba para inoculación experimental y la otra mitad para el estudio histopatológico. I.a inoculación experimental se hacia previo tratamiento del trozo de nódulo por e! método de Sáenz. 
CONDICIONES ETIOLOOICAS DE LA APARICION DEL ERITEMA NUDOSO

Condiciones generales de la zparición de la enfermedad.

EDAD

Debré. Sáenz y calaboradores estudiaron 40 casos de zritema nudosos en niños menores de 15 años.

El más joven de sus enfermos tenía 2 años y el de mayor edad, 14 y medio años. Según la edad, los casos se repartian en la siguiente forma:

$$
\begin{array}{lrlrlrl}
\text { de } & 1 & \text { a } & 5 & \text { años: } & 5 & \text { casos } \\
\text { de } & 5 & \text { a } & 10 & \text { años: } & 20 & \text { casos } \\
\text { de } & 10 & \text { a } & 15 & \text { años: } 15 & \text { casos. }
\end{array}
$$

Proporciones semejantes han descrito Comby, Lewin. Wallgren y Morquio, dando la mayor frecuencia alrededor del 8.9 año. Por nuestra parte estudiamos 31 casos. No padimos recoger un mayor número de casos, porque nuestra clientela hospitalaria recurre frecuentemente donde el médico cuando la enfermedad ya es avanzada. Asi, en nuestro caso. tuvimos que prescindir del estudio de varios enfermitos, en los cuales el eritema nudoso casi ya habia evolucionado. No eran apropiados para nuestro estudio, porque nuestro deseo era observiar exta lesión en pleno período evolutivo.

El enfermo más joven tenía 2 años 8 meses y el de mayor edad, 14 años. Según la edad, nuestros pacientes se repartían de la siguiente manera:

$$
\begin{aligned}
& \text { de } 11 \text { a } 5 \text { años: } 3 \text { casos } \\
& \text { de } 5 \text { a } 10 \text { años: } 12 \text { casos } \\
& \text { de } 10 \text { a } 15 \text { años: } 16 \text { casos. Es decir, en propar- }
\end{aligned}
$$
ción. nurestros enfermitos eran de mayor edad.

Las diferentes edades estaban representadas en la siguiente forma:

Edad

Cascs

$$
\begin{array}{ccccccccc}
2 \text { años } 8 \text { meses } & 5 & 8 & 9 & 10 & 11 & 12 & 13 & 14 \\
1 & 2 & 4 & 2 & 6 & 5 & 7 & 3 & 1
\end{array}
$$

Como se ve en nuestras observaciones. la mayor frecuencja del eritema nudoso se presentó alrededor del $10 .^{\circ}$ a $12 .^{\circ}$ วกั้อ. 


\section{ERITEMA NUDOSO}

El Prof, Raúl Cibils Aguirre presentó al Congreso Internacional de Pediairia en Roma, en 1937, un trabajo en que da a conocer sus investigaciones sobre la naturaleza tuberculosa del eritema nudoso.

Sus trabajos los realizó en colaboración del Dr. Andrés Arena y del Dr. Alfredo Sordelly, que realizaron la investigación bacteriológica y del anátomo patólogo Dr. Brachetto Briand, quien realizó los estudios histólógicos. En 1931 , Cibils Aguirre con Arena hicieron la primera demostración del bacilo de Koch en el nódulo por el métcdo de las teiriónculaciones. En 1933, Sáenz. Chevalier, Levy-Bruhl y Costi1 tubetculizaron el cay con inyección de maceración dis nóduic erimatoso. Los estudios posteriores de Debré confirmaron esos resultados. En 1932, Cibils Aguirre presentó un trabajo :en que se trató de demostrar la presencia de bacilos de Koch en el nódulo en 13 casos estudiados, de los cuales 4 casos fueron positivos.

Los 5 casos positivos que presentó en 1936 fueron publicados en los "Archivos de Medicine d's Enfants". No .se indica sobre cuántos casos estudiados.

El resumen de este trabajo es el siguiente:

1. En la totalidad de los 5 casos se ha podido demostrar en el nódulo del eritema nudoso la presencia del bacilo de Koch por el método de las inoculaciones, reinoculaciones sucesivas y iel cultivo correspondiente.

2. Además, en uno de escs casos la inoculación intra. ganglicnat del cuy fué positiva.

3." En otro de esos casos no solamente el cultivo direrto de ese nódulo ha sido positivo, sino que todavía pudiston verificar en muchos cortes del mismo nódulo la presencia de? bacilc de Koch fijado en pleno tejido enfermo.

Cibils Aguirre con sus colabcradores no encontraron los bacilcs con los caracteres tintoriales del bacilo da Koch en les nódulcs en el lumen de los vasos. sino en pleno tejids. fijados en él, por asi decir. Si no se los hubiese sncontraxlo sino en los vasos, se podría discutir el valor de tal verificación, atribuyéndola tal vez a una fase bacilémica del proceso - considerándolos como un virus de salida que los autares estiman de un interés palpitante, según los recientes trabajos de Trcissier y de Santis Monaldi, de Mach y de Sergant.

Estes trabajos fueron presentados por Cibils Aguirre 3 diversas sociedades cientificas en Uruguay, a la sociedad dz 
Pediatria Argentina, a la sóciedad de Dermatología Argentina y también al Congreso Internacional de Pediatría in Rema, en 1937. Fueron publicadas estas observaciones tam. bién en la Presse Medicale, en 1936.

\section{EL SEXO}

Parece tener poca influencia en el niño. Así, Debré y sus cclaboradores encontraton 19 hombres y 21 mujeres.

Por nuestra parte, se estudiaron entre 31 casos, 16 hombrés y 15 mujeres, es decir, porcentajes sensiblemente igualss. En el adulto, como se sabere, el eritema nudoso afecta a las mujeres de preferencia, 80 a 90 \% y en el trabajo de Debré la totalidad eran de sexo femenino. El colega Dr. Calderón. anátcmo-patólcgo del Hospital de tuberculosos adultos "Satn José". nos manifestó que durante los 9 años que él trabaja $m_{\mathfrak{r}}$ esé servicio. ni los clínicos ni él han podido encontrar más de 3 casos bien típicos de eritema nudoso. Esto está de acuerdo con el concepto ya antiguo de que el leritema nudoso es un.1 enfermedad del niño y del adulto joven.

\section{ESTACION DEL, AÑก}

Ejerce una influencia importante sobre la aparición d:! eritema nudosc la estación del año. Habría interés en saber si esta influencia estacional se ejerce sobre el germen patológico o sobre el terreno que lo recibe. Según la expresión de Werioger. al eritema nudoso es una enfermdad beliófnbs. Ella es excepcicnal en el verano, en cambio se observa sohre todo al comienzo de la primavera $y$ una recrudesencia ea otoñc, según Debré. En efecto, de sus 40 casos estudiados. 32 se observan en el invierno y en la primavera. 7 en otoño y 1 solamente en verano.

Por nuestra parte, observamos de 31 casos, 16 en primavera. 13 en invizrno, 1 caso en otoño y 1 caso en el vi"rano. Terromos proporciones sensiblzmente iguales. menos en stoñn en que nuestra observación no ocupa tal recrudescen. cia. El detalle de la distribución es el siguiente:

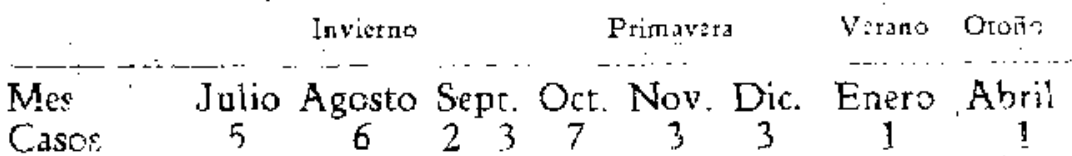

El eritema nudoso es una afección que se presenta cer preferencia en invierno y primavera. 
Es interesante notar que la aparición del eritema nudoso coincide con los mismos periodos del año en que se observan las poussées evolutivas de la tuberculosis pulmonar, las pleuresías sero-fibrinosas y las meningitis tuberculosas.

En este año pudimos apreciar un hecho interesante a es" te respecto. En los meses de abril y mayo, o sea, en otoño, tuvimos la ocasión de observar varios casos de eritema nndoso ( 5 hasta ahora). Coincide esta aparición de la tubercu1esis con un aumento también de la meningitis tubreculosa en uta misma época. Atribuimos esta circunstancia al tiempo excepcionalmente caluroso del otoño en este año. Se pucdz explicar este fenómeno por la irradiación solar excepciona!mente intensa en una época que habitualmente no la presenta. Existen, pues, condiciones climatéricas apropiadas para el desatrollo de las afecciones catarrales y, por ende, para la exacerbación y los brotes tuberculosos.

Ciertos caracteres clínicos del erizema nudoso.

El sitio de elección de los nódulos es la cara antero interna de las tibias (superficie de extensión de la pierna en forma más amplia) más raramente en los miembros supericres en donde prefiere la superficie de extensión di los antebrazos, excepcionalmente también en el muslo y frente, stgún Debré y colaboradores.

Resptecto al sitio de elección de los nódulos en nuestras cbservaciones, podemos decir:

Localización

N.? de casos

Adenitis. H." de cásos correspondientes

Superficie de extensión de ambas piernas

Superficie de extensión

de ambos antebrazos derecha 3 unilateral $<$

\begin{tabular}{c} 
izquierda \\
\hline
\end{tabular}

Muslo bilateral unilateral $<$ derecha 4

izquierda
$\begin{aligned} & \text { Brazo bilateral } \\ & \text { unilateral izquierdo }\end{aligned}$
$1=14$
$+$

unilateral izquierdo

$1=3$ 


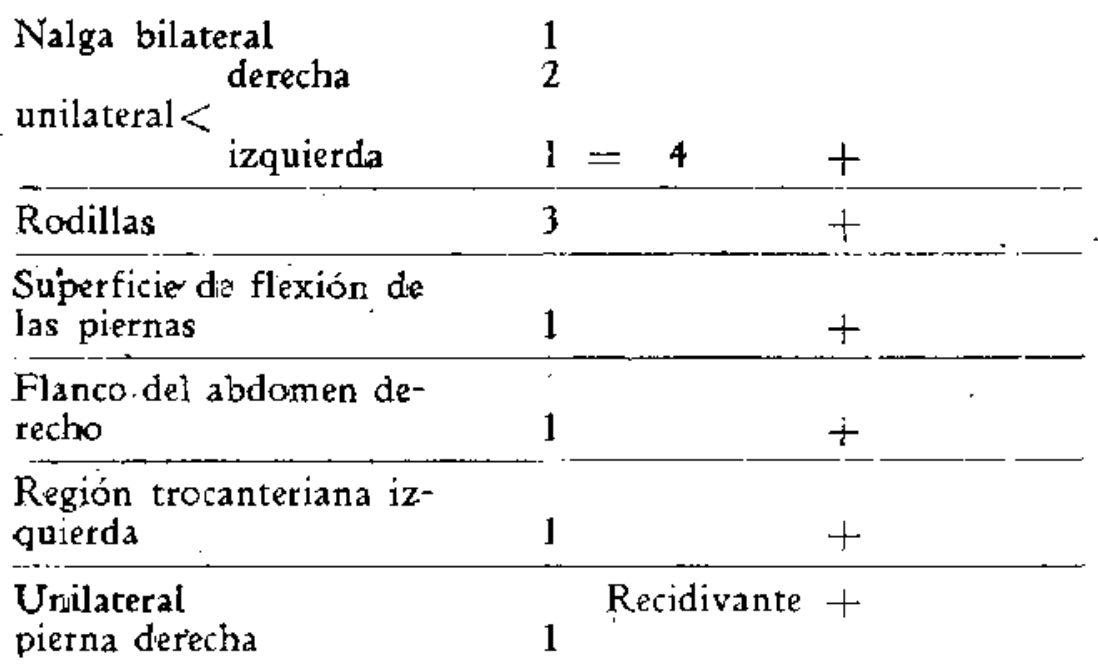

Como puede ver, en los 31 casos estudiados, la localización del eritema nudoso estuvo representada 30 veces en las superficies de extensión de ambas piernas. Es en realidad el sitio de predilección.

Después sigue en orden de frecuencia la superficie anterior de los muslos, 9 veces bilateral, 4 veces en el muslo derécho y 1 vez en el izquierdo; total. 14 veces.

A continuación, viene la superficie de extensión de los antebrazos, bilateral en 6 casos, al lado derecho en 3 casos y al lado izquierdo en 1 caso.

Las nalgas siguen en orden de frecuencia con 4 casos: uno bilateral, 2 al lado derecho y 1 al lado izquierdo. El lugar siguiente corresponde al brazo dos veces en localización bilateral y una vez con implantación únicamente en yl brazo izquierdo.

Las redillas eran sitio de eritema nudoso en 3 casos. Las demás ubicaciones de los nódulos son en realidad raras y descritas como muy excepcionales. como es la superficie de flê" xión de ambas piernas, el flanco abdôminal y la ragión tró canteriana. Consideramos un hecho sumamente interesante un casc de eritema nudoso unilateral, tratándose de una primo. infectión, cuyo complejo primario es pulmonar. Además. fué un caso recidivante. A propósito de un eriterna nudoso unilateral, quiero mencionar un .caso que nos relató el Prof. Sctcggie de un niño que se hizo una berida en un pie con un clavo. Esta lesión no tuvo tendencia a la cicatrización y después dẹ algunas semanas se presentó la adenitis inguinal co- 
arespondiente con la aparición también del eritema nudoso únicamente en esa extremidad en el sitio de elección. Si revisamos el esquema de localización del exitema nudoso, nos debe llamar la atención un hecho para el cual no tenemos explicación. Si los nódulos aparecen en un solo lado, lo bacen de preferencía en el lado derecho. Véase ubićación en gl mus10, 4 en el lado derecho; 1 en el izquierdo. Superficie de extensión de ambos antebrazos, 3 en el lado derecho y 1 en el izquisrdo. En la nalga hay 2 casos con localización en el lido derecho y 1 en el lado izquierdo. El caso de eritema nudoso unilateral es de la pierna derecha y recidivante en esé mismo lado.

Como se puede deducir del esquema, la adenitis correspondiente no ha faltado en ningún caso.

Debré y sus colaboradores hablan de eritomas nudosos Ifímeros. Por nuestra parte, las manifestaciones cutáneas han stdo bastante persistentes (por lo menos, 2-3 días de duración).

\section{La radiolcgía del tórax en el eritema nudoso.}

Según Debré y colaboradores, la aparición de los síntomas radiológicos coipcide, en general, con la erupción, te'atándose por supuesto de una tuberculosis de primoinfección. Las imágenes pulmonares radiológicas son idénticas a aquéllas que se encuentran en el paríodo inicial de la infección tubetculosa. constituyendo una prueba importante de la nat:raleza tuberculosa del eritema nudoso lén esos casos. La opacidad palcclógica se constituye en general muy pronto casi súbitamente. Estos mismos hechos han side ya comprobados por otros autores como Kobert, Ennberg, Carlboro, Nils Levin, Wallgren, etc.

Debré y sus colaboradores estudiaron entre sus 40 casos de eritema nudoso en niños la imagen radiológica $y$ en 28 pudieron cbservar modificaciones importantes de ella. I.a imagen más común era la de las adenopatías tráqueobrónquicas, con o sin reacción perifocal, que a veces puede set tan intensa que ocupa todo un lóbulo o casi la totalidad de él, lo que llaman "lobitis". En algunas ocasiones .encontracon el tomplejo primario en iniciación. A veces se presentaban pleuritis $y$ en un caso una pleuresía sero-fibrinosa concomitant? crm el eritema nudoso.

La localización inicial de la tuberculosis en é. eritzima nudeso puede ser extra-pulmonar. como en dos observaciotues de Cibils Aguirre. en que la puerta de entrada fué cu- 
tánea. (Véase caso del Prof. Scroggie de puerta de entrada de ana herida del piz por un clavo).

Wallgren opina que las manifestaciones clinicas de esas tuberculosis iniciales de localización extrapulmonar en el eritema nudoso, con punto die penecración peritoneal y articular en particular. pueden ser en tal forma discretas que pasan desapercibidas.

Pcr mi parte, puedo citar la observación del bijo de un colega. Cito tel siguiente caso por tratarse de un eritema nidoso, en dinde la puerta de entrada del bacilo dis Koch ąit ro la encontré descrita en la literatura.

M. A. G. -6 años. A mediados de enero. o sia. 4 semanas antes, el dentista le obturó el primer molar deriecho inferior. Tres semanas después, los padres notan aparecer on la región submaxilar derecha una adenitis que aumenta de tamaño en forma más o menos rápida. El niño se pone pálido y la temperatura se eleva. Un colega prescribe para la adenitis, sulfathiazol en dosis de $0,10 \mathrm{gr}$. por kgr. de peso. Esta medicación se suministra durante 6 días. Como no se riotara una influencia favorable. el niño es traído de un puebi? necino para examinarle.

Antes que nada. me llamó la atención una adenitis submaxilar del tamaño de un huevo de paloma, adherida firmemente al maxilar inferior, frente a los primeros molares era de consistencia dura poco dolorosa, sin síntomas de inflamación muy aguda. Un eritema nudoso típico se presentó $y$ cuva localización era en los sitios clásicos de las extremidades in:feriores, con su característica adenitis dolorosa del ángulo in. ferior del triángulo de Scarpa. La fiebre oscilaba entre 39 a $40^{\circ}$. Se zfectúa un hemograma que revela una ligera leucocitocis con una franca desviación hacia la izquierda.

\begin{tabular}{|c|c|}
\hline 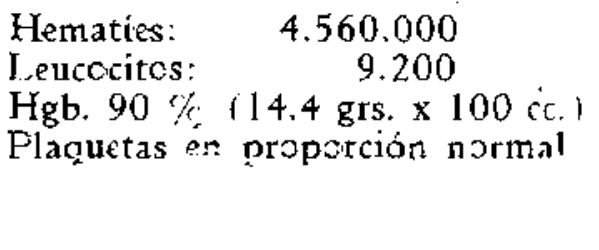 & $\begin{array}{ll}\text { Eosinofilos: } & 0.5 \\
\text { Juveniles: } & 2 \frac{2}{} \\
\text { Bacilifermes: } & 25.5 \\
\text { Segmentados: } & 48 \\
\text { Linfocitos: } \quad 13 \\
\text { Monocitcs: } \quad 11\end{array}$ \\
\hline
\end{tabular}

La radioscopía pulmonar resultó $\cdot(-)$. Se efectúa una radiografía dentaria de los molanes que se encuentran frente a la adenitis submaxilar. Se observa entre ef primer molar obturado y el saco dentario del molar de segunda dentición una amplia zona necrosada y las raíces des molar obturado 
rudimentarias y carcomidas. En vista de esta imagen radiológica, el dentista extrae el molar. No se encuentra pus en la cavidad alveolar. Se aprecia sólo una zona necrosada con escasas fungocidades. La raíz del molar está necrósada y el cuello tiene también una zona de necrosis circundante.

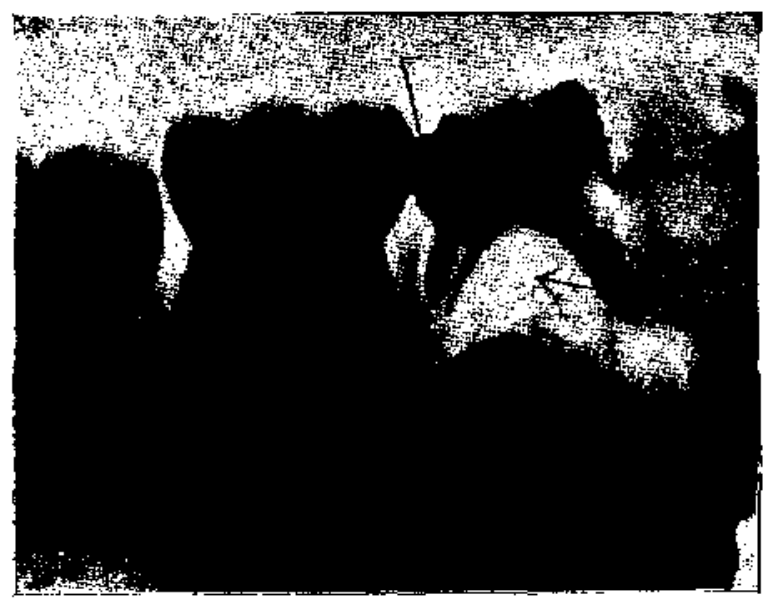

Una vez declinada la fiebre, se efectúa una prueba do velccidad de sedimentación globular que da $18 \mathrm{~mm}$. La reacción tuberculinica hecha en esta época en forma de Petruschky resulta intensamente positiva can flictenas. A las 3 semanas después de iniciada la adenitis submaxilar se reblandece. La punción efectuada en esa ocasión da salida a un pus verdoso. algo espeso, de aspecto del pus piógeno. El examen bactiriológico del pus, efectuado en forma directa por el Dr. Alfonso Costa, dió bacilos de Koch sin mayor dificultad.

Considerado este caso retrospectivamente, podemos concluir qué se trata de un aritema nudoso por primoinfección. En este caso, el punto de entrada del bacilo de Koch al organismo ha sido el molar obturado.

Esta observación tiene un especial interés, si la consideramos desde el punto de vista de los faces primarics tuber culoscs extrapulmonares. Se trata aquí de un caso in que esta puerta de entrada del bacilo tuberculoso era para nosctros una vía todavía desconocida y que tampoeo la encontramos descrita en la litzratura sobre tuberculosis infantil.

En resumen. Debré y sus colaboradores encontraron en el eritema nudoso alteraciones radiológicas pulmonares en Ios dos tercios de los casos en los niños. 
Nuestras experiencias al respecto son las siguientes: $(\mathrm{En}$ lo posible ejecutamos en cada enfermo una radioscopia acompañada de una radiografía):

\author{
N. ${ }^{\circ}$ de icasos
}

Adenopatía hiliar bilateral

7

Adenopatía hiliar izquierda 6

Adencpatía hiliar derecha 5

Complejo primario en evolución 4

Adenofatía hiliar y paratraqueal derzcha con sombras de condensación pulmonar en el lóbulo medio derecho (Atelectasia) 2

Adenopatía paratraqueal derecha 2

Adencfatía hiliar bilateral con infiltración parahiliar

Adenopatía hiliar bilateral y paratraqueal derecha. Atteilectasia del lóbulo infericr izquierdo y diseminación

Corresponds al eritems

1 nudoso unilateral y rocidivante.

Sombras hiliares marcadas 1

Radioscopia y radiografía pulmonares negativas. Pesteriormenta resultaton positivas

Como se desprende del esquema, de los 31 casos nuestros de eritema nudoso, 28 presentan una radiografía pulmonar positiva con alteraciones evidentes, 1 caso con lesiones sospechosas y 2 caser negativos. Como se ve, nuestro porcentaje de Fcsitividad de alteraciones pulmonares radiológicas es muy superior al dé Debré y sus collaboradores, haciendo el examen en el momento de la presencia del eritema nudoso.

Reaccicnes de la tuberculina en el eritema nudoso.

En la infancia, de 40 casos estudiados por Debré y colakoradcres, 37 tuvieron la reacción tuberculínica positiva $v$ 3 casos la presentaban negativa. Estos autoras explican est:? Fecho diciendo que una cuti o intradermo reacción negativa 
no basta para eliminar la etiología tuberculosa de un eritema nudoso, porque la alergia cutánea a la tuberculina puede ser retardada.

Los resultados que nosotros obtuvimos en las reacciones tuberculinicas del eritema nudoso son los siguientes: Do los 31 casos sólo en 29 se efectuó la reacción tuberculínica y en 2 casos no se ejecutó, porque se temieron reacciones muy violentas. En uno de ellos la madre tuvo un reritema nudoso 16 añes antes. En ambos, la radiografía reveló adenopatía hiliar y uno de ellos un complejo primario en evolución. De los 29 casos sometidos a las reacciones tuberculínicas podemos exponer los siguientes resultados:

Reacción tuberculínica

N." de conos

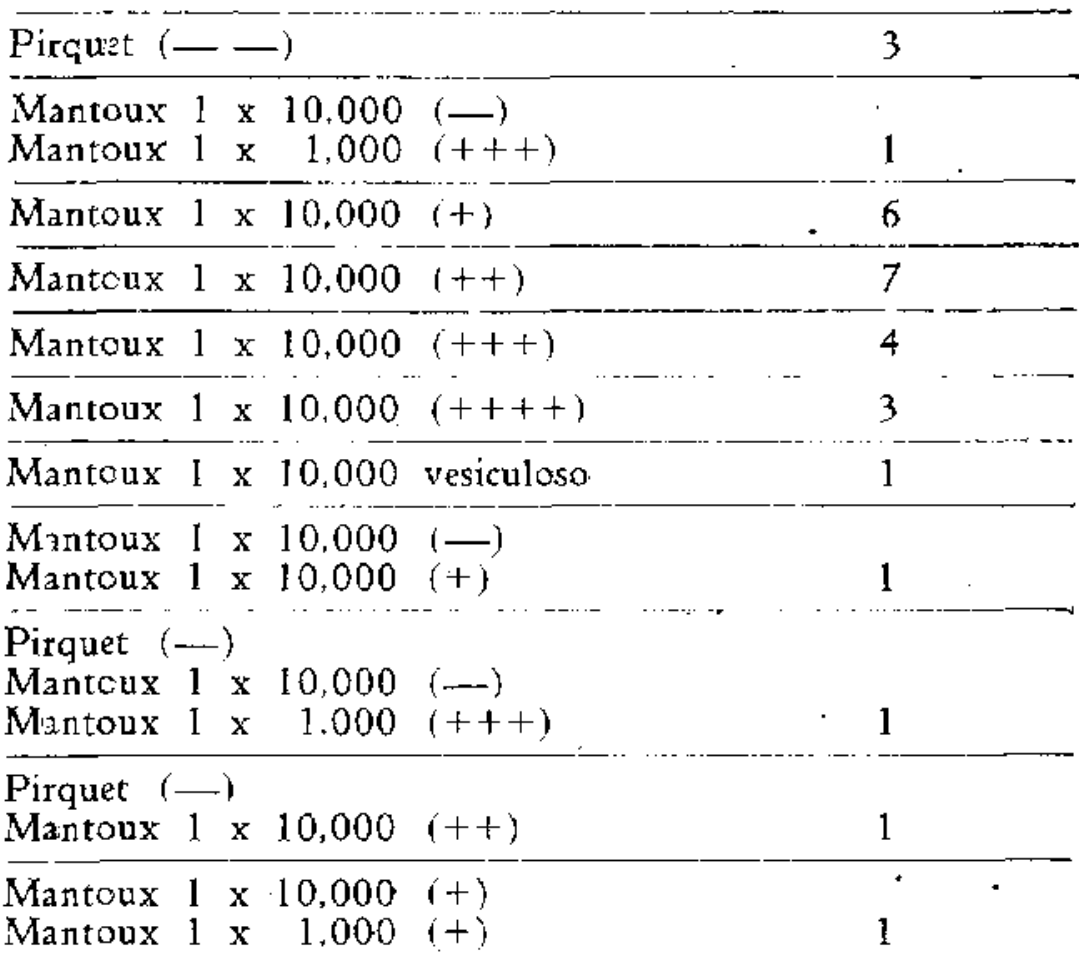

Si observamos el conjunto de estos nesultados, podemos decir que las reacciones en general no han sido muy intensas. (Se bicieron todas con tuberculina nacional que, como sabemcs, nos da reacciones siempre menos intensa que la tuberculina de Koch "Behring"). Sólo se efectuaron reacciones en 
29. casos, pues en 2 de los 31 . se temió una reacción muy viclenta, debido al cuadro clínico también intenso.

\section{La velccidad de sedimentación en el exitema nudoso.}

La sedimentación globular oscila en nuestros casos entre 14 y $21 \mathrm{~mm}$. como valores menores sólo en 15 casos. I.a mayoría de los casos son superiores a $27 \mathrm{~mm}$.. alcanzando hasta $90 \mathrm{~mm}$. Se comprende que así sea, porque todas nuestras observaciones son de eritema nudoso de primo-infectiones.

Investigaciór del bacilo de Kach en la expectoración rocog̣ida per el lavado gástrico.

Debré y colaboradores examinaron el desgarro en 27 exfectcraciones. En 14 casos encontraron el bacilo de Koch per cultivo e inoculación. Nunca obtuvizron el bacilo al examen directo. Por nuestra parte. hicimos el examen del desgarro en forma directa sobre 15 casos y 1 por inoculación. Todos resultaton negativos, por lo cual no atribuimos gran importancia a esta investigación.

Investigación del bacilo de Kech en les nódulos cutáneos.

Esta investigación fué realizada por Debré y colaborsdores en 18 niños y 10 adultos y sólo 2 veces pudieron porez en evidancia el bacilo tuberculoso en la nudosidad.

La técnica de la inoculación que usaton es la de Sáenz, que también para nosotros empleó el Dr. Costa.

Se procede en la siguiente forma:

Ncsetrcs realizamos en total la investigación en 29 de lcs 31 casos estudiados. No obtuvimos ningún caso con inosulación positiva sobre 29.

La investigación del bacilo de Koch en la adenitis correspendiente (ángulo infericr del triángulo de Scarpa o grupo correspondiente de la axila a la nudosidad de la extremidad) la realizamos también en 29 casos. No obtuvimos ningún re alutado pcsitivo usando il mismo procedimiento de Sáenz.

Se practicó para ella la biopsia del nódulo y su corres. pendiente adznopatía. Cada biopsia se dividió en la mitad y se envió una parte para investigar el bacilo de Koch por ino. culación y la otra para su examen histopatológico.

A continuación va un resumen de los protocolos de las incculaciones, un resumen de la técnica seguida y de los resultados alcanzados. 
Resumen de la técnica seguida y de los resultados alcanzados en las inoculaciones practicadas con material de biopsias de niños con eritemá nudoso.

Pata la inoculación se siguió la técnica recomendada por A. Sáenz y L. Costil (Diagnostic Bacteriologique de la Tubercuilose. Masson et Cía. París, 1936, pág. 142).

Esta técnica consiste en:

1.9 Cortar el trozo de tejido en finos fragmentos.

$2,{ }^{\circ}$ Triturarlo en un mortero con arena.

3. Tratarlo con ácido sulfúrico para destruir la flora asociada.

4." Neutralizar con soda.

La inoculación se hizo siempre en la región inguinal de? cuy.

Cicmo regla general, se inocularon 2 animales con cada muestra, y se obsicrvaron habitualmente, ocho semanas antes de sacrificarlos.

En total se inocularon: 99 cuyes. de los cuales 97 ls fueron con material de biopsia y 2 cuyes lo fueron con material obtenido de lesiones sospechosas encontradas en otros cuyes.

De las 99 inoculaciones en animales se utilizaron $68 \mathrm{v}$ fracasaron 31 .

De las 31 inoculaciones perdidas lo fueron por:

6 animales exraviados.

25 animalés muartos espontánea y precozmente.

Analizando los resultados obtenidos, ellos se pueder clasificar en la siguiente forma:

I. Casos en los cuales se inoculó ganglio y nódulo.

Fueron 19 con sil siguiente tesultado:

Negativos: 19.

Pesitivos: 0 .

$1,2,3,4,6,7,9,10,16,17,20,21 ; 22 ; 24: 26 ; 27 ; 28$; $29 ; 31$.

II. Cascs en que sólo se inoculó el ródulo (la inoculación del ganglio fracasó en 2 y no se hizo en 1 ).

3 casos, todos negativos, y son el 5 , el 14 y el 23 .

III. Casos en que sólo se inocularon ganglios son 5 . (La incculación del nódulo fracasó en 3 casos y no se hizo cr. 2). Estos 5 casos son todos negativos y tienen los siguientes números: $8,11.15,25,30$. 
IV. Casos en que se perdió la inoculación del nódulo y del ganglio son 2 , el 18 y el 19. (En ambos fracasaron todas las inoculaciones).

A estos casos cabe agregar los númetos 12 y 13 de la lisra, iss que no fueron inoculados.

Si sa considera el total de inoculaciones procedentes de distintos enfermos en cuanto a nódulos se tiene sólo 22 utilizables, y todos ellos resultaron negativos.

Revumen de los pretcroles de las inoeulaciones.

H.D. H.

Ganglio: inoculaciones N."

$67 / 41$ el 15-VII-4I: muere al 74 dia. aut.: negativa.

68/41 el 15-VII-41: muere al 13 dia; aut.: negativa.

Nódulo: 69/41 cl |5-VII-41: desaparecido.

70/41 el 15-VII-41: muere al 38 dia: aut.: negativa.

2.- - J. A.

Ganglio: $34 / 41$ el 30 del IV: sastificado al 86 doa: aut.: negativa. 35,41 el 30 del IV: detarecido.

Nódulo: $32 / 41$ el 30-1V-41: muere al 11 dia; avt.: negariva.

$33 / 41$ el 30-IV-41: sacrificado a] 67 día; aut.: negativa.

3.-M. M.

Ganglio: $115 / 40$ el 16-XII-40: sacrificado al 68 dia: aut.: negativa.

$116 / 40$ el 16-XII-40: sacrificado al 68 día; aut: negativa.

Nódulo: $117 / 40$ el 16-XII-40: sacrificado al 68 día: zat.: negativa.

$118 / 40$ el 16-XII-40: muere al 4 dia.

4.-N. B.

Ganglio: $99 / 40$ el 26-XI-40: sacrificedo al 63 dia; ant.: negativa. 100/40 el 26-XI-40: sacrificado $1+63$ dia: aut.: regativa.

Nódulo: 101/40 el 26-XI-40: sactificado al 63 dia: aut.: negativa 102/40 el 26-XI-40: sucrificado al 63 diai aut.: negativa

5.-G. C.

Ganglio: $95 / 40$ el 14-X1-40: muere al 3 dia.

95/40 el 14-XI-40: muere al 3 dia.

Nódalo: 97/40 el 14-XI-40: sactificado al 75 dia; aut.: atgativa 98/40 el 14-XI-40: muere a! 3 día.

6.-L. B.

Gatglio: 89/40 el 30-X-40: sserifiado al 71 dia: aut.; negativa. $88 / 40$ el 30-X-40: müre al, 2 dia.

Nódulo: $87 / 40$ el $30-\mathrm{X}-40$ : sacrificado as 71 día: aut.: negativa. 90/40 el 30-X-40: sarificado al 71- dia: out.: negativa. 
7.-S.P.

Ganglio: $83 / 40$ el 29-X-40: sacrificado al 71 día: aut.: negativa,

$84 / 40$ el $29-X-40$ : sacrificado al 71 did; lat.: Degativa.

Nodulo: $85 / 40$ el 29-X-40: sacrificado al 71 dia: aut.: negativa. $86 / 40$ \&] 29-X-40: muare al 5 dia.

8.-G. P.

Ganglio: 81/40 ei $16-\mathrm{X}-40$ : muere al 2? dia: :ut, negativa.

$82 / 40$ \& $16-X-40:$ sacrificado al 84 día aut.: negativa.

Nódulo: No se inoculó.

9.-S. G.

Ganglio: $77 / 40$ at $14-X-40$ : satificado al 7 t di: : aut.: negativa.

$78 / 40$ it $1+-X-40:$ sacrificado al 74 dia: aut. Hagativa.

Nódulo: $79 / 40$ el 14-X-40: sacrificado al 74 dia: aut.: negutira.

80/40 el 14-X-40: sacrificado al 74 dia: aut.: negativa.

10.--N. V.

Ganglio: $71 / 40$ el 4-X-40: sacrificado al 66 dia: zut.: nzgativa.

$72 / 40$; $4-\mathrm{X}-40$ : acrificado al 68 dia: aut: negativa.

Nódulo. $73 / 40$ el $4-X-40:$ muetc al 8 diú.

$74 / 40$ el $4-X-40:$ sactifiado al $66 \mathrm{di}:$ : aut.: regativit.

1).-A. G.

Ganglio: $67 / 40$, 4-X-40: sactificado al 67 dia: aut.: negativa.

$68 / 40$ el $4-X-40$ : sacrificado al 67 dia: iut: negativa.

Nódulo: $69 / 40$ al $4-X-40$ : muere al 3 dia.

$70 / 40$ al $4-X-40$ : muere a' 4 dí.

12.--M. L.

No sc inoculó ganglio ni nóduto.

I 3.-R. F.

No ta inozlúó ganglio ni nódulo.

I +. - A, B.

Yódulo; 38/40 el 8-VIII-40: muere al 4 dia.

$39 / 40$ al 8-VIII-40: muexe al 45 dia; aut.: negativa.

Ganglio: $43 / 40$ ef $8-V I[1-40$ : muere al 12 dia: aut: negativa.

44/40 el 8-Vill-40: rock al 3 dia.

15.-E. M.

G.nglio: - 51/39 al l I-X-39: desaparecido.

$52 / 39$ e) $11-\mathrm{X}-39$ : sacrificado 2154 dia: ant.: nagativ.

Nòdulo: No se inoculó. 
$16 .-1.5$.

Nódulo: $53 / 39$ el $27-X-39$ : desaparecido.

54/39 e] $27-X-39$ : sacrifirado al 40 dia: aut.: negatimu.

Ganglio. $55 / 39$ al $27-X-39$ : sacrificado al 40 dia: aut.: negativa.

$56 / 39$ el $27-X-39$ : sacrifiotdo al 40 día: aut.: negativa.

17.-F, O.

Nódulo: $57 / 39$ et 27-X-39: sacrificado al 40 dia: aut.: negativa. $58 / 39$ of $27-\mathrm{X}-39$ : desaparecido:

Ganglio: $63 / 39$ el $28-X-39$ : racrificado al 38 dia; aut.: negativa. 64/39 el 28-X-39: sacrifi:zdo al 38 dia: aut.: negativa.

Nćdulo: $65 / 39$ el 28-X-39: sacrificado al 61 di: a at.: negativa. 66/39 el $28-X-39$ : sacrificado al 45 dia: aut.: negaciva.

18. -V.G.

Nódulo. 33,39 el 26-VIr1-?9: mivere al 5 diz.

Ganglio: $34 / 39$ di 25 yill-39: muere al 5 dia,

19.-R. F

Ganglio: 35/39 al 26-VIII-39: muere al 5 dia.

Nódulo: $36 / 39$ el 26-VIII-39: muer al 5 dia.

20.-R, R.

Ganglio: 23/40 el 11-VIJI-39: sacrificado al 71 dia: aut.: negativa.

Nódulo: 24/39 el 11-VIII-40: sacrificado al 71 dia: aut.: nag :tiva.

$2 !-$ E. B.

Ginglio: 19/39 el 64VIJ-39: sacrificado al 69 dia: aur.: negativas.

20/39 il 6-VII-39: sionificado al 68 din: aut.: negativa.

Nödulo: 21/39 el 6-VII-j9: muere al 55 dia: aut.: negitiva,

22/39 el 6-VII-39: sacrificado al 68 dia: zut.: negativa.

22.-I. G.

Nódula: 31/39 12-VIII-39: sacrificado at 64 dia: aut.: Se entontraton nódulos catcosos visierales $y$ ganglionates, pero ne regionales al sitio de inoculacion. Wo se encontaton builirs de koch al ex:men directe del pus inseoso $y$ el examen hir. telógico no demostró lesiones tub?rculosas sino lesiones infla.. matorias sin carácter especifico. Una dz ssta; muestras caseosas fué reinoculada al cuy sin producir an il lesiones tobirculo:s.

Ganglio: $32 / 39$ el 12-V1Il-39: sacrificado al 64 dia: aut: negatiw?. 23.-R. M.

Nódulo: $79 / 41$ el 30-IX-41: eacrificado al 75 dias out.: nzgativa. 80/41 e 30-IX-41: sacrific:do at 77 dis: aut.: negarica.

G.nglio: Tơ se inoculó. 
24.-L. C.

Nódulo: 63/41 el 5-VII-41: muete al 81 dia: aut.: negativa.

64/41 el 5-VII-41: muere al 102 dia; aut.: negativa.

Ganglio: $65 / 41$ \& $5-\mathrm{VII}-41$ : desaparecido.

66/4l el 5-VII-41: muere al 24 día: ant.: negativa.

25.-R. V.

Nódolo: 29/39 el 12-VIIl-39: desaparecido.

Ganglio: $30 / 39$ ef 12-VIlI-39: muere al 54 did: aut: lesiones solpechosas: se rénocula con número 49 y $50 / 39$ animales gite se autopsian al 62 y 30 dias: no se encuentra tuberculosio: el examren bistológico también fúé negativo. (Dr. Guzmán).

26. - O. P.

Nódulo: $90 / 39$ el 16-XII-39: sacrificado 51110 dia; aut.: negativa. Ganglio: 91/39 el 19-Xll-39: muere al 7 día.

96/39 el 19-XII-39: sacrificado al 110 dia; aut.: negativ.

27.-V.S.

Ganglio: $89 / 39$ el 16-XII-39: sacrificado at 96 dili; act.: negativa.

Nódulo: $88 / 39$ el 16-X1l-39: sacrificado at 110 dí?: aut.: megativa.

28,-R. S.

Ganglio: 75/39 el 4-XI-39: sacrificado al 151 dia; ant.: negativa.

Nódulo: $76 / 39$ el 4 -XI-29: sacrificado al 32 dia: jut.: negativa.

$77 / 39$ : 4-XI-39; sacrificado al 32 dia; :ut.: negativa.

29.-L. A.

Ganglio: $63 / 40$ el $28+1 \mathrm{X}-40$ : sacrificado al 66 día: aut: negarive. $64 / 40$ el 28-1X-40: maere al 9 dia.

Nódula: $65 / 40$ el $28-\mathrm{IX}-40$ : sacrificado al 102 día; aut.: negatisa. $66 / 40$ el 28-IX-40: maere al 2 dia.

30.-Y. H.

Ganglio: $49 / 40$ el $11-\mathrm{IX}-40$ : muere al 8 dia.

$50 / 40$ el 11- IX-40: sacrificado al 84 dia; aut.; negativa,

Nódulo: 51/40 el 11-IX-40: muere al 8 dia.

$52 / 40$ el $1 \cdot 1-I X-40$ : muere lal 8 día.

3i.-J. C

Ganglio: $3 / 40$ ef $16-[-40$ : sacrificadio al 82 dia: aut.: negativa.

Nófulo: 4/40 e! 16-I-40: sacrificado al 82 dia; aut.; negativa. 
Estudio bistclógico de las lesiones cutáneas del eritema nudoso.

Con el objeto de imponer al lector en detalle sobre la histopatología del eritema nudoso, queremos reproducir integras las opiniones de los diferentes autores que más se han ccupado de esta materia.

Según Debré, Sáenz y colaboradores, hasta ahora jamás se encontraron en los nódulos lesiones histológicas típicas de tuberculosis folicular. Según Debré y colaboradores, se obtuvieron lesiones que semejan a las que Landouzi, León Bernard y Henri Gougerot nos enseñaron como tuberculosis no folicular.

El estudio histológico de los nódulos y de los ganglios los efectuamos con el fin de precisar la imagen histológica de ellos y buscar el bacilo de Koch en ellos.

Por primera vez fué encontrado el bacilo tuberculoso por Landouzy. Laederich y Richet hijo.

Debré con sus colaboradores y Eug Normand examinaton en total 30 biopsias de eritema nudoso; de los cuales 20 fueron practicadas en niños y 10 en los adultos. Se bicieron observaciones de nódulos bien recientes, aparecidos pocas horas antes. unos en plena madurez y otros en vías de extinción.

Las lesiones del eritema nudoso, según Debré, presentan los caracteres comunizs de la inflamación sin ningún carárter especifico de la tuberculosis: estas altetaciones son idénticas en todos los casos y no presentan más que variaciones de intensidad.

Localizadas sobre todo en la hipodermis y pudiendo interesar una parte del dermis, las lesiones del eritema nudoso son caracterizadas en su estado inicial por la transudación de fibrina que se infiltra en los tractus conjuntivos lobulando el tejido adiposo hipodérmico. La fibrina se deposita en largos filamentos sembrados de leucocitos de diferentes tamaños. comprendiendo sobre todo mononudieares.

En esta especie de substratum fibrinoide van a constituirse focos inflamatorios más o menos voluminosos redondeados o erizados de prolongaciones que se insinúan en los tejidos periféricos. El centro del foco está formado de leugocitos en donde predominan a menudo los polinucleares. Los núcleos de esos leucocitos están a menudo deformados y en picnosis. Simultáneamente, en cierta parte central del foco. la materia fíbrinoide está fragmentada y tiende a disolverse. 
En la periferie del foco se encuentran elementos mono-nucleares de diferzntes tamaños contenidos en las mallas de la fibrina, penetrando en los intersticios de las células adiposas del tejido conjuntivo y a veces en la túnica de ciertos vasos que ellos disocian profundamente.
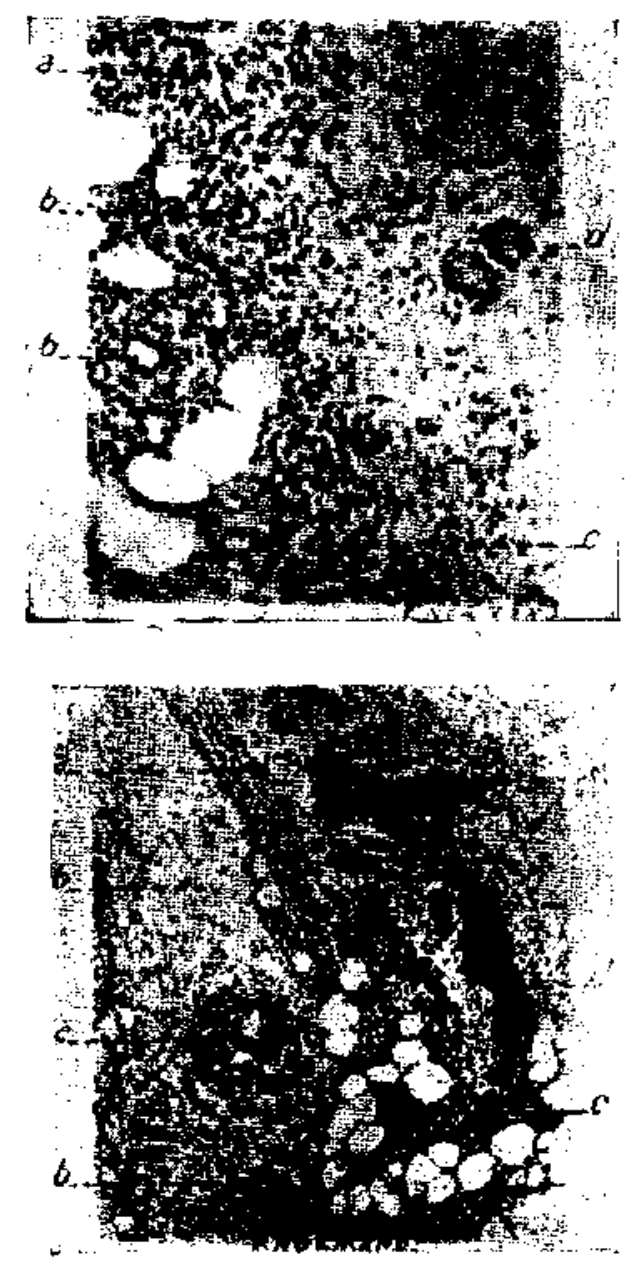

Esquema de corte bistológico del eritema nudoso (según Debré y colaboradores).

Las glándulas sudoriparas situradas en los confines de la grasa hipodérmica y del dermis son bastante profundamente tccadas por esas lesiones que lo disocian y constituyen alrededor de ellos y de sus canales excretores especie de manguitos. 
Estos pueden envolver los canales muy arriba en el dermis. En fin. se descubre a veces en esos focos inflamatorios la prisencia de algunas células multinucleadas, recordando a las células gigantes tuberculosas. Peto ellas quedan siempre aisladas y no se encuentran jamás lesiones que adopten una estructura fo! $i^{-}$ cular.

Wallgren considera que todos los autores que examinaron el cuadro anatómico del eritema nudoso no han sido capaces de demostrar tuberculosis típicas (Brunsgard. Ernberg. Jadascohn, Levandowsky, Symes y otros). Se trata de focos de infiltrados celulares especiailmente perivasculares y también periglandulates (especialmente leucocitos) en las partes más profundas del cutis y de la sub-cutis. los que a veces también alcanzan hasta el periostio ( $\mathrm{H}$. Koch). Característica es la presencia de eritrocitos que pueden presentarse en cantidades tan grandes que se puede hablar de un infiltrado hemorrágico o de una hemorragia. Los vasos que están comprometidos en el proceso inflamatorio presentan con frecuencia alteraciones endoflebíticas. Algunas veces han sido obsarvadas células gigantes (fagocitos de la grasa, según Symes). Lo que de por sí no habla a favor de tuberculosis (Jadassohn, Lewandowsky). Ernberg considera que el cuadro anatómico semeja a una pápula tuberculínica, lo que no es confirmado por otros autores (Brunsgard).

En 1929 decía Wallgren: tampoco ha sido posible comprebar bacilos tukerculosos en los tejidos patológicos. El hace saso omiso de las observaciones de Landouzy y Gutmann. los que no asegurarian que el etitema nudoso sería provocado localmente por bacilos tuberculosos. El caso de Gutmann apanas parece haber sido un eritema nudoso y la observación de Landcuzy es tan aislada y única que se debe pensar en una coincidencia. Hablan contra la naturaleza bacilar del eritema nudcso las numerosas experimentaciones animales negativas que se realizaron con material de los nódulos. Basta citar a (Brunsgard, Feer. Hegler. Holland, Pollak, Symes, Vetlesen y otros más).

Tachau, en su colaboración dz la colección de Dermatologia de J. Jadassohn, dice que las investígaciones histológicas de Brunsgard, Campana, Chotzen, Darier. Frieboes, Gans. Jedassohn, Loederich y Richet, L. Philippson, Unna. Torok y otros demostraron que dominan el cuadro procesos inflamaterics muy intensos, los que tienen su punto de partida $\mathrm{d}$ ? las venas subcuráneas y por eso se localizan de preferencia en las capas profundas de la cutis y subcutis. Mientras en el cuer- 
po papilar y en las capas superficiales y medianas de la cutis se pueden comprobar sólo dilatación vascular y generalmente un edema no muy intenso. Se encuentran más profundamente infiltrados inflamatorios de carácter hemorxágico. Estos acompañan los vasos, además los folículos. las glándulas sudoriparas y penetran entre los lobulillos adiposos profundamente en el tejido subcutáneo, donde en un grado más avanzado puede producirse la atrofia proliferante (alli se encuentran también, como en un caso de Jadassohn, las conocidas células gigantes provenientes de las células adiposas).

En caso de una lesión de mayor intensidad, el tejido conjuntivo libre de la cutis es inundado en mayor escala por células de exudado. Los infiltrados se componen, fuera de cé lulas de tejido conjuntivo tumefactas y proliferadas, las que evidencian abundantes mitosis, casi exclusivamente de linfocicos y leucocitos polinucleares. A la inversa del eritema exudativo multiforme, predominan generalmente las últimas ( $T \ddot{\text { - }}$ rök). Además, se encuentran casi siempre eritrocitos en gran cantidad, los que pueden constituir considerables aglomeraciones. Sólo Unna los echa de menos en sus preparados. El encontró, en cambio, como Gans, Mastzellen. pero no muy numerosos. Sobre presencia de Plasmazellen habla Darier, Darier y Jadassohn, Mallein y L. Philippson encuentran células gigantes en algunos de sus casos. Estas se encontraron en los cascs de Jadassobn en cantidades considerables. Ellas estaban situadas en los lobulillos adiposos y tenían generalmente núcleos periféricos en cantidad considerable y un protoplasma vacuolizado bastante regularmente. Tejido tuberculoide se echa de menos. Darier, sin embargo, comunica en un caso de un nódulo de 12-15 días la presencia de células epitelioidzas. Tubérculos típicos también faltaban aquí. Donde se ha encontrado estructura tuberculoídea (por ejemplo, en el caso dr Laurent $y$ Abel en Pons), el diagnóstico de eritema nudoso apenas se puede considerar como seguro. Se encuentran, además. procesos proliferativos en los endotelios. En las venas subcutáneas, los endotelios están engrosados y aumentados en número. Por esto, a veces, se puede producir una obliteración total de la vena. Darier habla también de procesos periflebiticos. A la inversa del eritema exudativo multiforme, faltan casi por completo alteraciones del epitefio. En donde existern son muy insignificantes.

Oscar Gans, en su histología patológica, dice que llas modificaciones tisulares del eritema nudoso se efectúan, a la inversa del eritema exudativo multiforme, primer lugar, en 
la cutis. La epidermis se compromete secundariamente. Esto se aprecia en aquellas regiones en que las infiltraciones celulares de ia cutis o dermis se acercan a la capa superficial, donde ésta se presenta aplanada. Aquí puede estar borrado el sistema paFilar en el centro de la prominencia nodular. En general, la epidermis no participa en las modificaciones; asi, falta en ella casi completamente el edema intra y extracelular. Sólo en casos aislados se aprecia al lado de un espacio linfático dilatado una tumefacción celulat uniforme, como también formaciones mitósicas más numerosas.

Toda la red capilar del dermis menos la del cuerpo papilar está dilatada y rodeada de un infiltrado celular muy denso. Este infiltrado se circunscribe a los vasos y a su vecindad. En su constitución participan al lado de células de tejido conjuntivo tumefactas linfocitos y leucocitos polinucleares y en forma aislada también las Mastzellen, mientras que las Pilasmazellen nunca se observan, por lo menos, en los foros más recientes. En los vasos mismos, especialmente en las arterias, se puede comprobar una tumefacción a veces evidente de los endotelios, una modificación que se encuentra más frecuentemente en los nodulos antiguos que en los recientes. En estes vasos se encuentra entonces una intensa infiltración de la pared hemorrágica-inflamatoria. Además, se presentan en la inmediación de los vasos ingurgitados pequeños extravasados hemorrágicos, que son los determinantes de aquella coloración particular contusiforme de los nódulos. Estos extravasados también se observan. aunque no en forma tan extensa, en los nódulos más recientes; pero a veces también pueden faltar. Fuera de los infiltrados celulares perivasculares, la epidermis no es más rica en células como de costumbre. En cambio, en este sector, un edema de intensidad variable separa las fibras del tejido conjuntivo y las elásticas. Pot lo tanto, el edema alcanza más allá de la zona de infiltración. En la zona de infiltración las fibras del tejido conjuntivo y elástico están separadas, casi destruídas, y en parte no se pueden comprobar.

En casos aislados descritos como formas persistentes del eritema nudoso, se encontraba en vez de los poco característicos manguitos celulares perivasculares, una atrofia progresiva del tejido adiposo, la que conducía a la formación de células gigantes y células de carácter epitelioídeo. En estos casos, por reg:a general, se presentaban alteraciones progresivas de los vasos en forma de trombosis e inflamaciones de la pared vascular (tromboflebitis), los que conducian a una obliteración Farcial o total de los vasos (mesoarteritis obliterante). Se en- 
cuentrati, por lo tanto, todas las transiciones, desde cuadtos simples inflamatorios infiltrativos hasta los cuadros que permiten una semejanza con las alteraciones tisulares tuberculoides. Estas lesiones tisulares se pueden aducir sin más ni monos en apoyo de la especialidad de la lesión. Este carácter tuber ${ }^{-}$ culoide se encuentra, en efecto, en aquellas raras formas diel eritema indurado (Bazin), que no son ocasionadas por el bacilc tuberculoso.

Tiesde el punto de vista del diagnóstico diferencial, el eritema nudoso nos puede colocar por eso ante dificultades insalvables. Esto se comprende fácilmente si tomamos en cuenta las diferentes causas que se han aducido en la génesis de la enfermedad. Estas opiniones divergían desde los banales piógenos y sus respectivas toxinas hasta el bacilo tuberculoso o la espiroqueta pálida y aun hasta los agentes específicos desconocidos. Un hecho es seguro: la noxa que por via hematógena penetró a la piel con su acción, no alcanza más allá de as inmediaciones de los vasos cutáneos. Aquí se produce una reacción tisular inflamatoria en el sentido de una infiltración perivascular y edema del dermis con una consunción simultánea de las fibras elásticas. Este es un proceso que se puede denominar sin discusión, como inflamación localizada a los vasos del epidermis y sus inmediaciones. En todo caso, lo que se ha observado en la dermatosis metastásica estafilógenas, es decir, la circunscripción de las infiltraciones "infiltrados perivasculares más o menos extensos con dilatación vasculat y edema del cuerpo papilar y dermis", permiten aceptar desde e! punto de vista patogenético una cierta semejanza entre estaș alteraciones y el eritema nudoso.

Para Debré, Sáenz y demás autores que colaboraran, el eritema nudoso representa una lesión tuberculosa no folicular. como lo prueba la presencia, aunque rara, del bacilo de Koch en el nódalo. La investigación del bacilo de Koch al examen directo de un fragmento de nódulo obtenido por la biopsia es raramente positivo. Sólo en dos casos los autores mencionados pudieron constatar bacilos con rodos los caracteres del tuberculoso, tanto en su morfología como en sus particularidades de tinción. En ambos casos positivos las lesiones biscológicas eran particularmente intensas y el bacilo estaba ubicado tha pleno tejido inflamatorio y no en el lumen de un vaso. En uno de los casos se pudo confirmar la identidad tuberculosa del bacílo mediante Ia inoculación al cuy.

Debré y Sáenz opinan que el hallazgo con el microscopio del bacilo de Koch en ia nudosidad eritematosa es de un 
interés dectrinal considerable. Ello confirmaría su opinión que el elemento cutáneo del eritema nudoso no sería una lesión simplemente alérgica. sino una lesión inflamatoria ligada a la fresencia misma del bacilo tuberculoso. En resumen, estos autores censideran que el eritema nudoso, tanto en eil adulto como en el niño. es indiscutiblemente tuberculoso y debe ser ccnsidcrado como una verdadiera tuberculosis cutánea no fclicular fácilmente reabsorbible.

Respecto a este punto, el Prof. Herzog nos manifestó que aunque se encuentre en un tejido el bacilo de Koch, mientras no aparecen alteraciones morfológicas especificas en su histopatologia no se puede afirmar que esa lesión sea producida per el bacilo mismo.

Wallgren, refíciéndose a los trabajos de Cibils Aguirre, Debré y Lewkowicz. dice que eilos aparentemente le restan importancia al concepto de manifestación tubérculo-alérgica del eritema nudoso tuberculino-positivo.

Estas publicaciones indujeron a Wallgren a revisar sus ideas a! respecto y para ello realizó nuevas investigaciones por la inoculación. El material se refiere a 28 casos de eritema nudoso tuberculino-positivo. Sólo en un caso obtuvieron en forma irrefutabla la presencia del bacilo de Koch, pero en número muy escaso. Si se resumen todas las investigaciones hechas hasta septiembre de 1929. resulta que en total se afectuaron hasta entonces 113 inoculaciones de eritema nudoso en el cuy. Sólo en 4 casos se comprobó la presencia de bacilo de $\mathrm{Kcch}$. es decir. una vez entre 25-30 casos. En cortes hisțológicos el bacilo de Koch se encontró sólo 2 veces en 60 casos. o sea. 1 vez en 30 casos.

Por esta razón. Wallgren hace las siguientes preguntas sobre esta cuestión: ¿Por el hecho de haberse comprobado ocacionalmente la presencia de bacílos tuberculosos en los nódulos está demostrado fehacientemente que los bacilos están en relación directa etiológica con los nódulos?

$\mathrm{Si}$ íos nódulos fueran siempre el producto de la acción local de los bacilos tuberculosos como otras formas de tuberculosis cutánea bacilar, entonces habría que esperar que el germen no se encuentra como en estos casos de eritema nudoso en forma excepcional, sino bastante regularmente. A esto hay que agregar que las alteraciones anatómicas del nódulo no son es pecíficas para la tuberculosis y que tanto el cuadro anatómico rcme el clínico de los casos tuberculino negativos es semejante a los casos tuberculino-positivos. 
El que no estamos autorizados sin más ni menos para deducir una etiología tuberculosa por la presencia de escasos bacilos tuberculosos en un órgano, eso se subentiende.

Así, la presencia de bacilos de Koch en las lesiones linfogranulomatosas en un tiempo hizo pensar en que esos gérmenes tuvieran una relación etiológica con esa lesión Hoy en día todos aceptan que los bacilos tuberculosos se encuentran como saprofitos latentes $e$ inofensivos en los ganglios y tejidos linfogranulomatosos sin tener importancia patogénica.

En los miños, en el período en que se presenta el eritema nudoso existe siempre una diseminación hematógena. Una tal diseminación bacilar que habicualmente no provoca manifestaciones patológicas, puede explicar satisfactoriamente la presencia ocasional de escasos bacilos tuberculosos latentes en los nódulos.

Por otra parte, la presencia de bacilos tuberculosos en los nódulos, ¿excluye que éstos sean de naturaleza alérgica desdo el punto de vista patogenético?

Las erupciones de eritema nudoso tienen una evolución clínica completamente diferente a las manifestaciones tuberculosas cutáneas. Los nódulos son desde el punto de vista anatómico de naturaleza muy diversa y la reacción que se desarrolla en los nódulos cutáneos es mucho más intensa y más fugaz que la reacción local común del organismo frente a bacilos tuberculosos virulentos. Este otro modo de reaccionar debe ser provocado por la alergia.

Por esta razón, los bacilos tuberculosos encontrados en muy escasas excepciones en los nódulos eritematosos deben considerarse probablemente inofensivos, sin relación etiológica con la erupción.

Por lo tanto, no bay razón, en presencia de los nuevos hallazgos bacteriológicos, apartarse del concepto que considera al eritema nudoso como una manifestación patológica alérgica inespecífica.

Por nuestra parte, el Dr, Alberto Guzmán, nuestro anátomo patólogo, hizo el estudio histológico de los nódulos, haciendo cortes. de los cuales una parte fué destinada al estudio histológico. Por lo tanto, los primeros cortes fueron coiloreados con una hemateína eosina para estudiar en ellos las alteraciones microscópicas. Los cortes segundos fueron teñidos con fuxina para investigar el bacilo de Koch in situ.

Nuestros resultados son los siguientes:

En total, se examinaton 31 biopsias. 


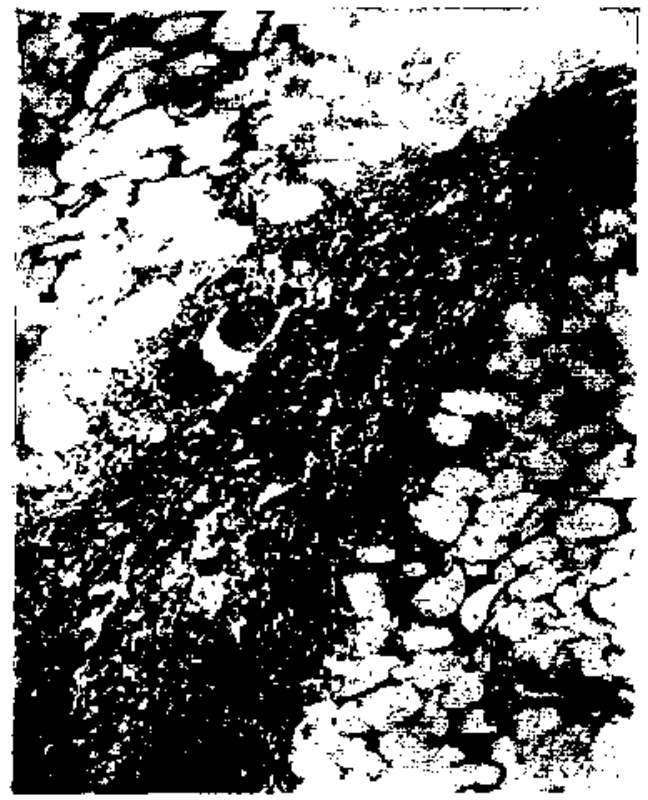

Fig. ?.

Cortc de eritema nudoso: engrosamianto edema infiltrido inflamatorio acompañado de cicialas gigantes. Tejido conjuntivo del hipodarmo. (Aumento menos).

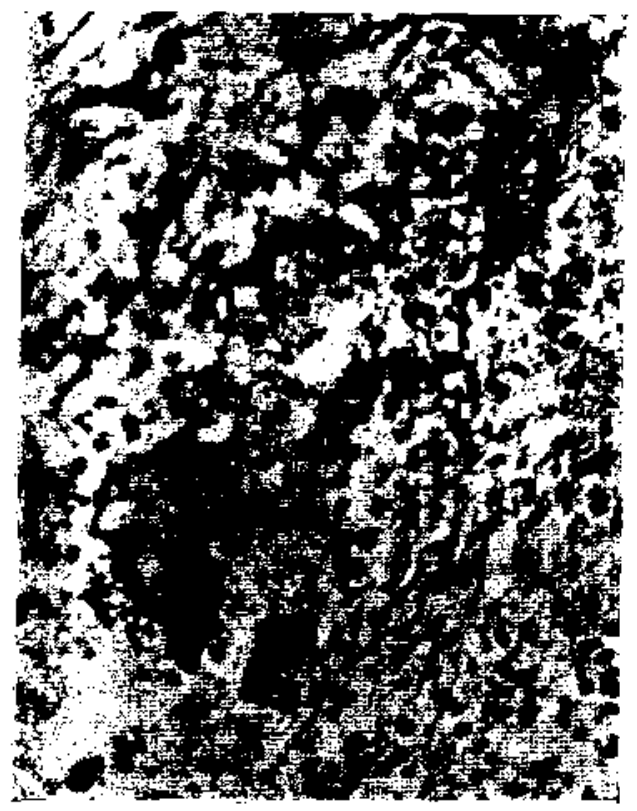

Fig. 4.

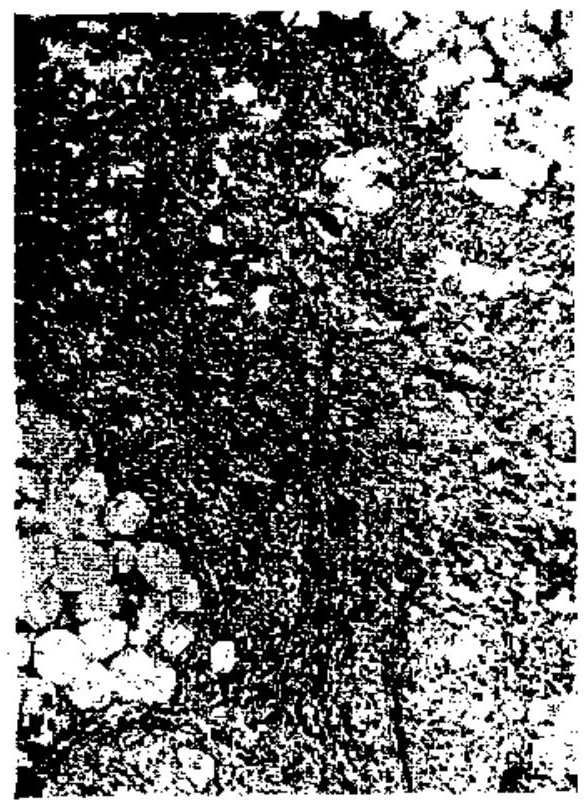

Fig. 5.

Corte de eritema nudoso: Infiltrado infl matotio con engrosamierto $y$ edema del te. do conjuntivo del hipodermo con célul gigantes.

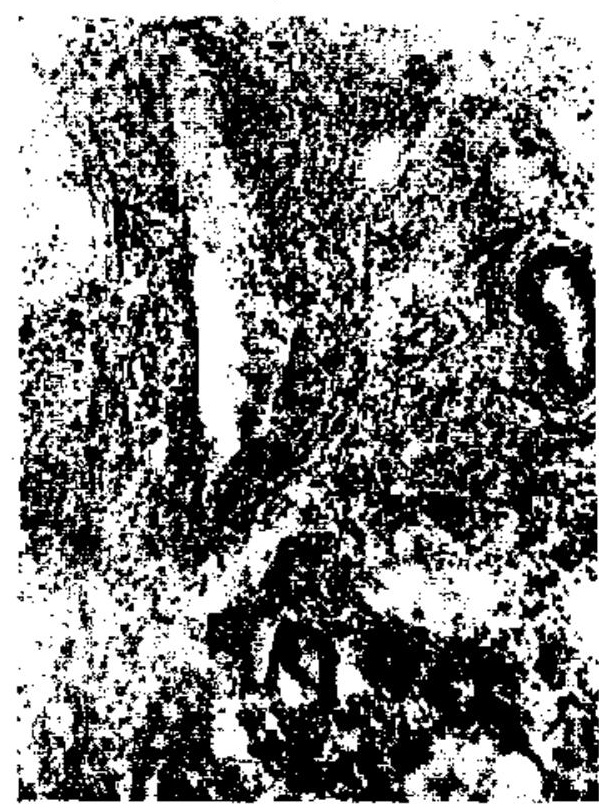

Fig. 6.

Cotta de eritema nudoso correspondiente a parte profunda del dermis con infiltracio nes inflamatorias intensas airededor de 10 pasog. 
Según nuestras observaciones, podemos manifestar que el fircceso inflamatorio de eritema nudoso no presenta caractereia específicos del rejido tuberculoso.

La localización del proceso es de preferencia en la hipodermis y compromete tarabién con menor intensidad el dermis, especialmente en sus partes profundas, donde se localizan con predilección alrededor de los anexos de la piel. Al nuestro juicio, el proceso inflamatorio es difuso sin poder apreciar formaciones nodulares circunscritas. Hacia la profundidad, el proceso sigue los spetums de tejido conjuntivo a invade conjuntamente el tejido celular subcutáneo. Los vasos, especialmente las venas, están a menudo comprometidos por el infiltrado inflamatorio. Estos infiltrados inflamatorios están ccnstituídos según la antigüedad de la lesión. Al comienzo predominan leucocitos polinucleares y más tarde las células redondas pequeñas, medianas y elementos de tipo histiocitarics y proliferación de fibroblastos. También el infíltrado inflamatoric puede ir acompañado de elementos gigantocelulares. En el tejido conjuntivo del hipodermo puede encontrarse o edema inflamatorio o proliferación del tejido colágeno. No hemos encontrado coloraciones positivas con los colorantes de la fibrina. Pueden o no ir acompañadas de bemorragias. En el dermis los infiltrados son perivasculares y màs discretos que en el hipodermo. Hemos encontrado también en un caso pequeñas necrosis grasosas focales.

La investigación directa del bacilo de Koch en los nódulos ha resultado negativa en todos ellos.

Examen histopatológico de la adenitis correspondiente a los. nódulos eritemaltosos.

Por nuestra parte, hicimos esta investigación con el objeto de buscar en los ganglios correspondientes a las. zonas afectadas por el eritema, algunas alteraciones morfolkgicas. 'A pricri, ésta no la podemos esperar, porque considerando el eritema contusiforme como un proceso alérgico, lo que se desprende de las investigaciones de Wallgren y otros autores $y$ tamtién de nuestra modesta experiencia, sólo debemos suponer alteraciones funcionales én dichos ótganos. Es decir, en ellos ce desarrollan procesos que no dejan modificaciones orgánicas. Ncs basamos para creerlo asi, en el concepto que el Prof. Scroggie tiene sobre la ubicación del eritema nudoso en relación con el sistema linfático.

A continuación van sus ideas al respecto. 

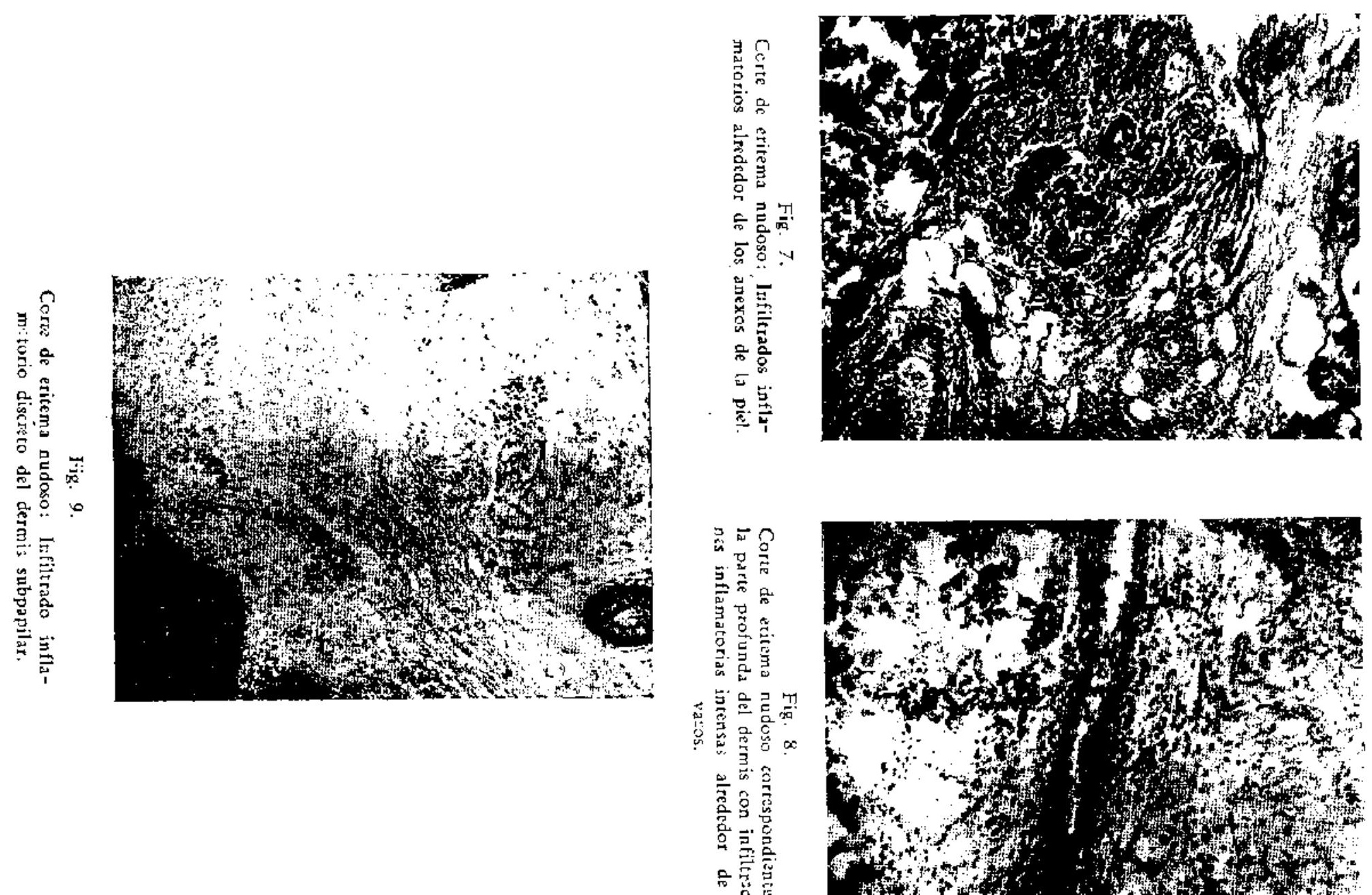
"Iniciada la infección tuberculosa primaria se producen bacilemias que poco a poco estimulan el sistema retículo endotelial hasta producit la sensibilidad especifica llamada alergia tuberculosa. Juegan en este proceso un rol importante los tejidos y la linfa, que recoge los detritus bacilíferos y, como se comprende además. es indudable el rol de los ganglios linfáticos satélites. Quedan, en consecuencia, estos productos tubérculo tóxicos en la linfa y en los ganglios, produciéndose por este motivo elementos que contratrestan la acción de estos productos. Así se genera la sensibilisina específica para el alergeno que presentan en este caso los bacilos de Koch o sus productos.

En estas condiciones, en ẹl sistema linfático $y$ en especial en sus ganglios (cementerio de bacilos de Koch) estimulados por estos detritus, debe existir un dispositivo de defensa que dificulta y retarda la circulación linfática (ectasia). Además, la estación de pie, los ejercicios físicos, la posición sentada y la acción de la gravedad determinan una predisposición mayor a este mismo fenómeno de ectasia linfática. Ahora. en aquellas regiones de la economía en que las vías linfáticas son más largas y actúan los fenómenos y la fuerza de gravedad antes dicha, la retención línfática será mayor y serán los sitios de elección de esta manifestación cutánea tuberculo. sa. Los sitios de predilección de los nódulos son las superficies de extensión de las piernas y después las superficies de extensión de los antebrazos. Los linfáticos de las zonas primeramerrte nombradas son los más largos de las extremidades inferiores. porque desembocan en los ganglios del vértice dal triángulo de Scarpa. En cambio, los linfáticos de la superficie de flexión tienen sus ganglios correspondientes en el hueco poplireo. En las extremidades superiones los linfáticos de la su. perficie de extensión del antebrazo desembocan en los ganglios axilares; en cambio, los linfáticos de la superficie de flexión tienen sus ganglios satélite epitrodear.

¿Cómo puede explicarse según: estas corsideraciones el eritema nudoso?

Tenemos, por un lado, la bacilemia inicial comprobada por varios autores, o sea, la presencia del alergeno en la sangre y en los tejidos. Por otro lado. tenemos la ectasia linfática con la acumulación consabida en la linfa de la sensibilisina especifica, generadas por el proceso antes dicho. Repentinamente, el organismo, por condiciones inmunobiológicas directamente relacionadas con el sistema retículoendoteliat, cambia 
su manera de reacción con la alergia específica que en estos casos se traduce por una hiperergia. o sea. hipersensibilidad. Esto se manifiesta localmente por una inflamación linfovascular y tisulat que en clínica denominamos eritema nudoso.

En los casos de eritema nudoso ya pasada la primoalergia en períodos en que momentáneamente una enfermedad infecto-contagiosa, infecciones o alteraciones psíquicas o cons titucionales inhiben o debilitan la defensa hacia la tuberculosis. sobreviene bruscamente o una bacilemia (diseminación) o una hipoergia szguida de una hiperergia brusca general o local. En estos casos, el eritema nudoso está en relación con un: bacilemia brusca o cambios reaccionatios a Jérgícos después do un periodo más o menos largo de acalmia sintomática (sedimentación. leucocitosis, temperatura y buen estado general)"

Este concepto del rol patogénico de la ectasia linfátics del eritema nudoso, tiene su apoyo en el hecho ya conocido por muchos autores respecto al sexo.

Como ya lo dijimos, todos los que estudiaron el eritema contusiforme bajo este aspecto, y así también lo comprueban nuestras observaciones, consideran que el sexo parece tener poca influencia en la infancia. En el adulto, a la inversa, el sexu femenino es mucho más afectado por el eritema nudoso. Así Debré y sus colaboradores vieron que de 11: observaciones d? aduiltos y adolescentes todos pertenecian a'l sexo femenino: spgún ellos. no tendrían explicación alguna al respecto.

La mayor parte de los autores están de acuerdo en encontrar en el adulto el eritema nudoso en una proporción de 80 a $90 \%$ de müjeres. Así, los aucores nórdicos Usted y Johannesen entre 314 casos de eritema nudoso en adultos no vieton más que 29 casos en el hombre, o sea, en el $9.2 \%$.

Ahora bien, como sabemos, en la mujer adolescente y en la aduita entra en juego un nuevo factor que es la función senital. Como el aparato genital está en actividad periódica. es lógico que la circulación linfática también sea mayor en todos los linfáticos de la región pelviana. Con más razón sucede esto en el embarazo. Esta plétora linfática significa una ectasia de toda la circulación linfática que viene de las extremidades inferiores. Alquí tendríamos, pues, el momento propicio para la localización de predilección dél exitema nudoso. Con el objeto de contribuir al esclarecimiento de la patogenia del eritema nudoso, consideramos de utilidad hacer el estudio comparativo de las adenitis correspondientes en el triángulo de Scarpa. Para ello utilizamos un trabajo que se hizo en el servicio de cirugía de este Hospital. sobre el valor diagnóstico de 
las adenitis inguinales en las tuberculosis de la rodilia. En 135 cascs estudiados de tuberculosis osteoarticular de la rodi1la. comprobada radiológicamente y por los exámenes correspondientes, las biopsias de los ganglios del ángulo inferior del triángulo reveló alteraciones tuberculosas histopatológicamente indiscutibles, ya sea exudativas, caseificadas o productivas en el 100 \% de los casos. Cuando la biopsia fué negativa, siempre la clínica rectificó posteriormente otro diagnóstico y descartó con absoluta seguridad la tuberculosis.

Refiriéndonos al estudio histopatológico de las adenitis en el critema nudoso, ellas resultaron negativas para la tubercalosis en el $100 \%$ de todos los casos estudiados tanto en los cortes de congelación como en las inclusiones en parafina con cortes seriados. Debemos hacer notar que en los casos de biopsias de ganglios de tuberculosis osteoanticular la positividad para la tuberculosis se obtiene generalmente al primer corte de hielo. En muy pocos de estos casos fué necesario realizar cortes en parafina y seriados hasta encontrar lesiones histopatológicas de tuberculosis. Con estas experiencias hemos adquirido. a nuestro juicio, un criterio irrefutable para comprobar que en la patogenia del eritema nudoso no interviene el bacilo de Koch mismo con un teiido tuberculoso específico. A esto podemos agregar como un complemento la inoculación experimental negativa de todos los ganglios examinados. Ad más. no debemos omitir el becho aue el examen directo del bacilo de Koch en ilos ganglios resultó negativo en todos ellos.

Estudio comparativo entre la morfología de las reacciones tuberculínicas y del eritema nudoso tuberculino-positivo.

Basándonos en la definición clínica que dieron algunos autores scbre el eritema nudoso, consideramos de especial interés hacer el estudio comparativo entre la morfologia de las reacciones tuberculínicas y el eritema nudoso de origen tuberculoso en la infancia. Asi, al Prof. Pfaundler le of (Wiederhold) en su clase sobre el eritema contusiforme la siguiente definición de él: El eritema nudoso en la infancia, especialmente en la edad preescolar. escolar y 3." infancia es una "au. tepirquetización" del organismo.

El autor nórdico Ernberg considera al eritema nudose como la autcreacción de Mantoux del organismo infantil.

Consideramos entonces de interés hacer exámenes histopatológicos de las reacciones tuberculinicas intradérmicas. Buscando en la literatura encontramos que uno de los autores qui 
más estudios hizo sobre la inmunobiologia de la tuberculosis es el Prof. Bessau. Sus trabajos se basan en una infinidad de investigaciones morfológicas microscópicas sobre la inflamación local tuberculosa. De estos estudios dedujo el concepto del tubetculocito que, según él. es toda célula del mesenquima del organismo capaz de reaccionar especificamente frente al preducto vital del bacilo de Koch, la tuberculina. Bajo este aspecto considera a la reacción local tuberculínica como una reacción específica frente a la tuberculina circulante en el organismo. No es especifica en su morfología frente al bacilo de Koch, formando la conocida lesión folicular, sino frente a los productos de éste, es decir, a la tuberculina. Transmitimos sus ideas precisas sobte la reacción tuberculinica intradérmica, pues nos sirve de base a nuestro estudio morfológico de las reacciones de Manroux.

En un período avanzado de la reacción tuberculínica, el tuberculocito es mejor diferenciado, porque toda célula de inflamación debe pasar por un periodo de maduración. Provienen del endotelio vascular. Nosotros vemos las células epitelioideas características y en mayor cantidad no en las reacciones tuberculínicas recientes, sino en las reacciones tuberculinicas locales más antiguas en aquéllas en Jas cuales las manifestaciones inflamatorias ya han declinado completamente. Con este hallazgo histológico armoniza el hecho biológico que estas reacciones tuberculinicas antiguas muestran reacciones focales mucho más intensas que las recientes, en las cuales el tejido específico no ha madurado todavía.

Con el objeto de apreciar bien la evolución de las alteraciones morfológicas locales y poder aquilatar la acción de la tuberculina localmente en los tjidos, hicimos el estudio en distintas épocas de la inflamación tuberculosa local no folicular. En esta forma consideramos que no se nos pudieran escapar algunos detalles para el estudio comparativo que nos proponíamos. Especialmente, le dimos importancia al factor tiempo y después al factor cantidad de tuberculina. o sea, la concentración de ella para poder sacar algunas conclusiones al respecto.

R'ealizamos cortes histológicos seriados en una reacción al $1 \% / 00$ a las 24 horas, al $1 \% / 00$ a las 48 horas, al $10 / 00$ a las 72 horas y al $1 \%$ a los 7 días.

El resultado ha sido el siguiente: Estructura histológica igual a la de los nódulos del eritema nudoso en cuanto a calidad y distribución de las alteraciones. Sólo hay una diferencia de grado de intensidad de la lesión en el sentido de ser 


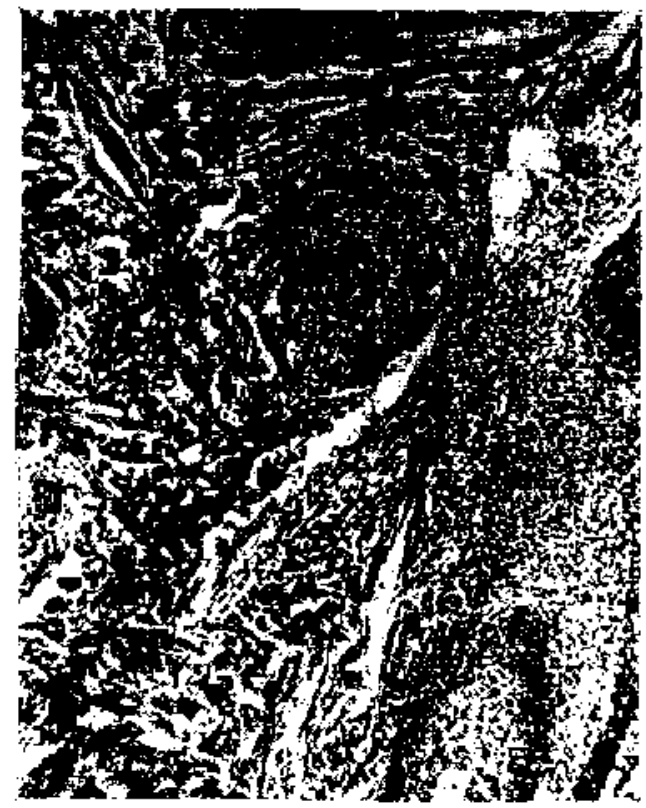

Jig. 14.

Corte de pápula de tuberiulina Mantoux al $1 \times 1.000$ a las 72 horas. Inflamación predominantemente linfocitari.z que en parte compromete el músculo erector del pelo. (Aumento meror). Biopsia 106/42.

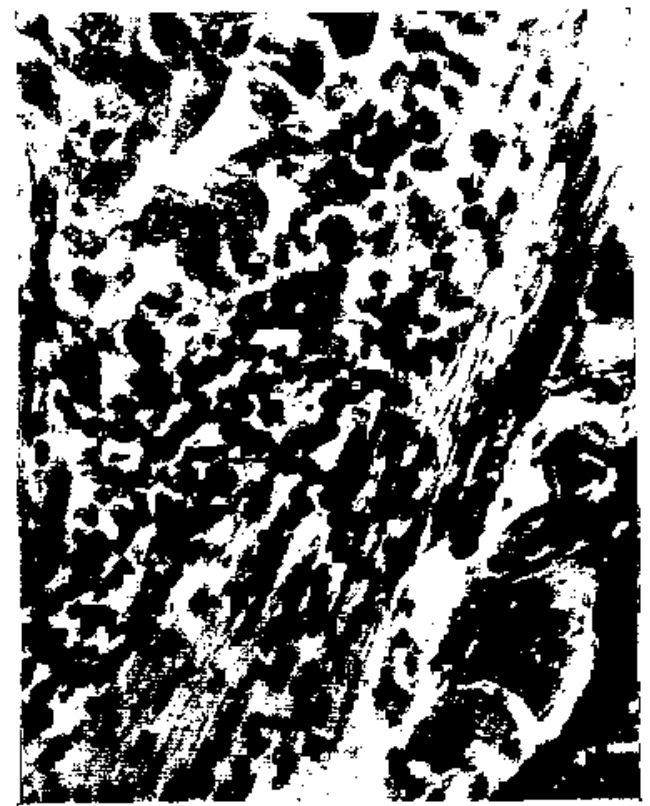

Fig. 15.

Corte de pápula de tuberculina Mantoux al $1 \times 1,000$ a las 72 boras. Inflamación predominante linfocitaria que en parte compromete el músculo enector del pelo. (Au-

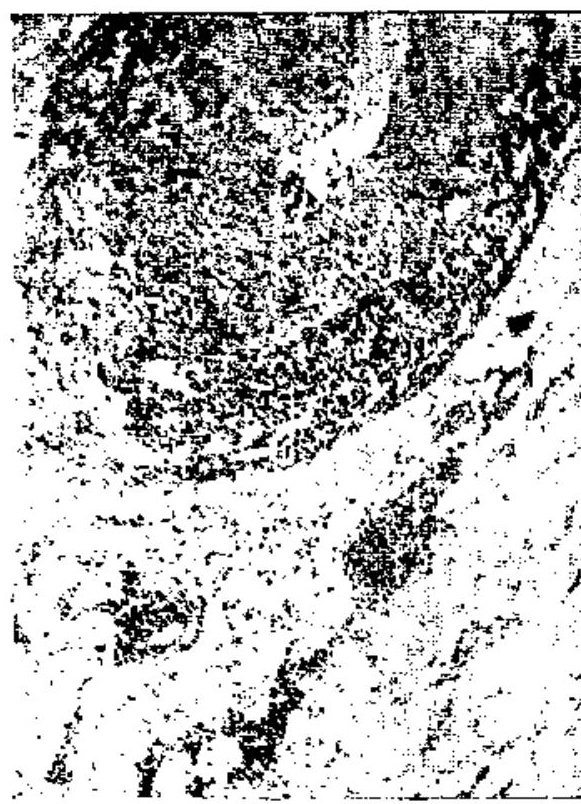

Fig. I 6 .

Corte de páputa de tuberculina Mantoux ] $x 100$ a los 7 dias. Intensos infiltrad. inflamatorios perivasculates del hipoderm (Aumento menor). Biopsia $110 / 42$.

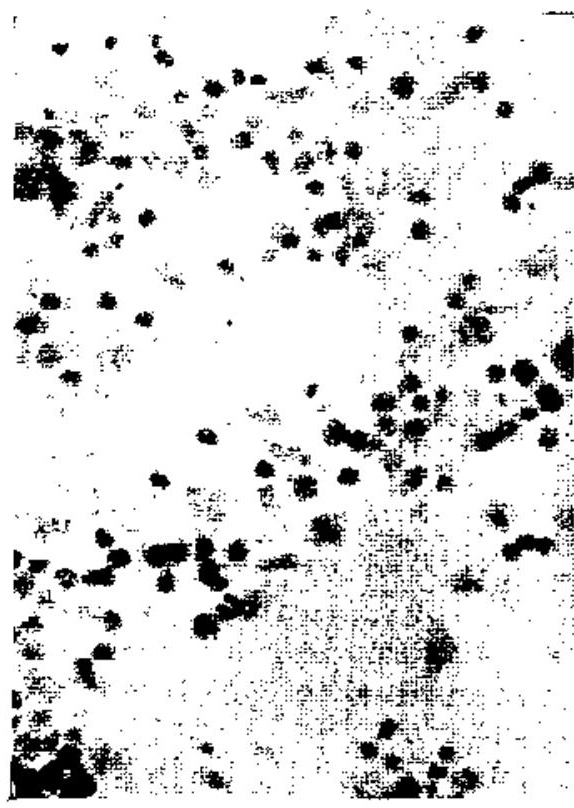

Fig. 17.

Corte de pápula de tubérculina Mantoux $1 \times 100$ a los 7 días. Infiltrado inflamatc torio con aumento mayor. (Células redond: e bistiocitos). Biopisia 110/\$2. 
mucho más intensas las alteraciones del etitema nudoso. Se acerca más a estas lesiones eritematosas en intensidad la estructura histológica de la reacción de Mantoux al $1 \%$ a los 7 días.

El estudio comparativo entre la histopatología del eritema nudoso y de las reacciones tuberculínicas se encuentra perfectamente dentro de un principio de inmunobiología de la tuberculosis. En realidad, debemos tener presente que en el individuo que está afectado por tuberculosis su organismo se encuentra en relación recíproca con el bacilo de Koch y sus substancias especificas. Sabemos también que los productos especificos del bacilo de la tuberculosis representan desde el foco de la enfermedad aquel estímulo que trata de llevar al organismo a su grado máximo de su capacidad de reacción. esfecialmente en los primeros tiempos de realizada la infección en el período de la diseminación nubetculotóxica. Es conocido el hecho también que al lado de este estímulo biológ:co tan intenso la suministración artificial de pequeñas cantidades de tuberculina en la piel para las reacciones tuberculíni. cas es insignificante.

Es asi como nos podemos explicar que en la compare ción morfológica del eritema nudoso con las teacciones do Mantoux no existe diferencia desde el punto de vista cualitativo (morfología en cuanto a calidad y topografía de los elementos inflamatorios), pero sí desde el punto de vista cuan. titative. es decir. de la cantidad de tuberculina que provocó las lesiones. En realidad, sólo una cantidad considerable dr tuberculina puede producir lesiones inflamatorias tan intensas que llegan hasta la necrosis de los elementos del tejido celular subcutáneo que simulan después las formaciones giganitocelulares. Analizando las reacciones de tuberculina al $10 / 00$ a las 24 horas, podemos constatar que las lesiones inflamatorias no tienen todavía una gran intensidad. En cambio, el estudio histopatológico de la reacción de Mantoux al $1 \%$ a los 7 dias, demuestra lesiones histopatológicas más intensas, a tal punto que ya presentan el comienzo de la necrosis de tejido. Si sobre esta alteración tisular actúa una noxa más enérgica representada por una cantidad considerablemente mayor de tu. berculina como lo es el organismo hipersensible en el eritema nudoso. tendremos las formaciones gígantocelulates. Por !o que se ve, es sólo cuestión de grado de intensidad lo que diferercia la morfología de la reacción tuberculínica de aquélia del eritema nudoso. Es, por lo demás, un hecho conocido que en el periodo agudo del eritema nudoso tenemos el momento en que existe la rnás intensa inundación del organismo por los productos específicos del bacilo de la tuberculosis. Es is 
bipersensibilidad tuberculosa del organismo humaro llevada al máximo. Es por todos conocido el hecho de que en esos cascs tenemos las más intensas reacciones tuberculínicas conocidas en sus formas vesicular o necrótica. Como se compren$\mathrm{d} \varepsilon$, la reacción tuberculínica que efectuamos artificialmente. jamás podrá provocar lesiones tisulares tan intensas como lo hace espontáneamente el organismo hipersensible inundado por considerables cantidades de tubetculina en su autoreacción biológica representada por el etitema nudoso.

\section{Conclusiones.}

En 31 casos de eritema nudoso estudiados bajo ciertos aspectcs clínicos como epidemiológicos, de sexo, edad, reacciories tuberculinicas, radiología y especialmente bajo el aspecto patogénico. Hegamos a las siguientes conclusiones:

1. $C$ Respecto a la aparición del eritema contusiforme, encontramos que en nuestro pais también se presenta de preferencia a fines de invierno y en la primavera. En este año excepcicnalmente por alteraciones climatéricas apareció con una mayor frecuencia no observada aún en el otoño.

2. En lo que al sexo se refiere, pudimos comprobar que no tiene predilección por alguno de ellos.

3. La edad de preferencia en el eritema nudoso es de los 10-12 años.

4. La radiología pulmonar dió una positividad de lesiones ganglio-pulmonares de $100 \%$.

$5 .^{\circ}$ Todos los eritemas nudosos que estudiamos eran tuberculino-positivos.

6. La localización de preferencia es la superficie $\mathrm{d} z \mathrm{ex}$ tensión de ambas piernas y le siguen en orden de fracuencia los musles, la superficie de extensión de ambos antebrazos. nalgas. brazos y rodillas. Nos ba llamado la atención la preferencia de localización en el lado derecho.

7. Las incculaciones experimentales efectuadas en 29 cascs, de los 22 eran utilizables para los nódulos y 24 para !cs ganglios, todas resultaron negativas para el bacilo de Koch.

$8 .^{\circ}$ Es estudio histopatológico de los nódulos es semejante al de los autores extranjeros en cuanto a ausencia de leciones tuberculosas específicas. El de los ganglios satélites tampoco dió lesiones tuberculosas específicas.

9. La investigación directa del bacilo de Koch en los nódulos y en los ganglios dió resultado negativo.

10. El estudio comparativo de los ganglios satélites del zritema nudoso con el de las lesiones osteoarticulares tubercu- 
lcsas de la rodilla, dió negatividad en $100 \%$ de los primeros y pcsitividad en $100 \%$ de los segundos.

11. El estudio comparativo de la morfología histopatclógica entre las reacciones tuberculínicas y el exitema nudoso $r \in v \in$ ló una semejanza absoluta en cuanto a calidad y topogralía de las lesiones y sólo diferencia en cuanto a intensidad de las alteraciones.

12. Por las razones anatómicas del sistema linfático de ios miembros expuestos más arriba, por la histopatología de los nódulos y de los ganglios satélites que no demuestra lesícnes tuberculosas específicas para el bacilo de Koch, la investigación directa del bacilo de Koch negativa en los nódulos y en los ganglios, eil estudio comparativo de las adenitis $c c$ rrespondientes entre lesiones tuberculosas. bacilares de la rodilla y el eritema nudoso, el estudio comparativo de la morfología de las reacciones tuberculínicas y el eritema nudoso que demuestra su identidad histopatológica, cteemos que el eritéma nudoso tuberculino positivo no es una tuberculosis cutánea per diseminación bacilar, sino que debemos seguir considerándclo como una diseminación tuberculosa tuberculotóxica, c sca, un froceso de alergia tuberculosa.

\section{Bibliografía.}

BAMBAClI B. - Experiencias clinicos soure eritema nudoso. Archivos del Hospital Roberto del Rio. Septiembre de 1931.

BESSAU G. - Inmunobiologie der Tuberkulo:e; Klinische Wochenschrift N." 8. 1925 .

CIBILS AGUIRRE R, - Congreso Internacional de Pediatria en Roma, 1937. DEBRE R.. SAENZ A., BROCA R. y MALLET R. - Etudes sur l'srythems noueux Revele Francaise de Pediatrie, N. 5, 1938.

GANS O. - Die Histologie der. Hautkrankideiten. Erythema nodosum.

JOHANNSEN N. - Beitrage zur Frage der Zusammenbanges von Erythima nodasum mit Tuberkulose und Gelerkrheumatismus.

Jahttuch für Kinderheilkunde Bd. 81, 1931.

SAENZ, A, y COSTIL 1. - Diagnostidque Bacterio!ogzque de la Tuberkulose. 1936.

TACHAU. - Annatomía patológica del exitena nodoso. Colecrión J. Jaáaschn. 1928 .

WALLGREN A. - Etythema nodosum, Pasthologische Anatomie en Handbuch där Kindertuberkulose de St. Engel y C. Pirquét. 1930.

WALLGREN A. - Eritema nudoso Del Tratado de la Tubercutosis Infantil 1940.

WALLGREN A. - Zur Pathogenese des Erythema nodosum. Monatsscbrift füt Kinderbeilkunde 80 bd., 1939. 